San Jose State University

SJSU ScholarWorks

Master's Theses

Master's Theses and Graduate Research

Summer 2010

\title{
A Qualitative Study of the Motivations of Runners in a Cause- Based Marathon-Training Program
}

Karin Ann Jeffery

San Jose State University

Follow this and additional works at: https://scholarworks.sjsu.edu/etd_theses

\section{Recommended Citation}

Jeffery, Karin Ann, "A Qualitative Study of the Motivations of Runners in a Cause-Based Marathon-Training Program" (2010). Master's Theses. 3812.

DOI: https://doi.org/10.31979/etd.f3up-kr73

https://scholarworks.sjsu.edu/etd_theses/3812

This Thesis is brought to you for free and open access by the Master's Theses and Graduate Research at SJSU ScholarWorks. It has been accepted for inclusion in Master's Theses by an authorized administrator of SJSU ScholarWorks. For more information, please contact scholarworks@sjsu.edu. 
A QUALTITATIVE STUDY OF THE MOTIVATIONS OF RUNNERS

IN A CAUSE-BASED MARATHON-TRAINING PROGRAM

\author{
A Thesis \\ Presented to \\ The Faculty of the Department of Kinesiology \\ San José State University \\ In Partial Fulfillment \\ of the Requirements for the Degree \\ Master of Arts
}

by

Karin A. Jeffery

August 2010 
(C) 2010

Karin A. Jeffery

ALL RIGHTS RESERVED 
The Designated Thesis Committee Approves the Thesis Titled

A QUALITATIVE STUDY OF THE MOTIVATIONS OF RUNNERS

IN A CAUSE-BASED MARATHON-TRAINING PROGRAM

by

Karin A. Jeffery

APPROVED FOR THE DEPARTMENT OF KINESIOLOGY

SAN JOSÉ STATE UNIVERSITY

August 2010

Dr. Ted Butryn $\quad$ Department of Kinesiology

Dr. Matthew Masucci Department of Kinesiology

Dr. Tamar Semerjian Department of Kinesiology 


\title{
ABSTRACT \\ A QUALTITATIVE STUDY OF THE MOTIVATIONS OF RUNNERS IN A CAUSE-BASED MARATHON-TRAINING PROGRAM
}

\author{
by Karin A. Jeffery
}

In the late 1980s, the nonprofit sector within the United States introduced a new philanthropic paradigm, the cause-based fundraising endurance-training program. Participants in such programs raise funds for a charitable cause and, in return, are coached to complete a marathon or other endurance event.

Cause-based training programs frequently use recruitment messages implying that the cause provides a guaranteed motivation to exercise. However, little research has examined this assumption. Therefore, the purpose of this study was to qualitatively research the motivations of runners in a charitable cause-based marathon-training program, particularly the relationship between the cause and the participants' motivations to train consistently. Results suggested that for most study participants, the cause became increasingly significant and meaningful as the program progressed, even for those who joined with no initial connection. These results may be significant both for cause-based training programs and for interventions to help increase general levels of physical activity. 


\section{ACKNOWLEDGEMENTS}

I cannot express my gratitude to everyone who helped this study become a reality. Here are just a few of the people whom I would like to thank:

My thesis chair, Dr. Ted Butryn, for your mentorship, for setting high standards, and for teaching me the skills I needed to meet them;

My thesis committee, Drs. Matthew Masucci and Tamar Semerjian, for also demanding the best and for providing constant support;

Dr. Shirley Reekie, Chair of the Department of Kinesiology, and Drs. David Furst, Jay Johnson, Peggy Plato, and Emily Wughalter, of the same department, for your support and insights, and for setting outstanding professional examples. It's been a privilege to work with each of you;

My study participants; I cannot thank you enough for donating your time, energy, and insight;

SeongKwan Cho, my classmate, fellow researcher, and best friend. I was very lucky to meet you at SJSU;

My family, especially my father, an eagle-eyed proof-reader;

My husband for his endless support;

And finally but most importantly, the late Tom Pomeroy, 32-year veteran of the San José State University Police Department. You are the reason and inspiration for this study. You are loved and missed. 
TABLE OF CONTENTS

Chapter 1: INTRODUCTION 1

Chapter 2: JOURNAL ARTICLE

Chapter 3: EXTENDED SUPPORT MATERIAL 25

$\begin{array}{ll}\text { Introduction } & 25\end{array}$

Statement of Purpose $\quad 29$

Definition/Description of Terms $\quad 29$

Delimitations 31

Limitations $\quad 31$

Summary $\quad 31$

Review of Literature $\quad 32$

$\begin{array}{ll}\text { The Marathon of Hope } & 32\end{array}$

Contemporary Cause-Based Training Programs 34

Team in Training 35

The AIDS Life//Cycle and the Avon Breast Cancer 3-Day Walk 36

Key Components of Cause-Based Training Programs 37

$\begin{array}{ll}\text { The charitable cause } & 38\end{array}$

The participant commitment 38

Commitment to fundraise 39

Commitment to prepare (train) for a pre-selected endurance event 39

Commitment to complete the endurance event 41

Theories of Motivation in Sport and Exercise Psychology 42

Self-efficacy theory $\quad 42$

Achievement goal theory 43

Self-determination theory $\quad 45$

Motivation in Exercise and Running $\quad 47$

Altruism, Charitable Volunteerism, and Cause-Related Physical Activity 52

Qualitative Research 55

Summary 55

Methods $\quad 56$

Participants $\quad 56$

Instrumentation and Equipment $\quad 57$

Background questionnaire $\quad 57$

Interview guide $\quad 57$

Digital voice recorders $\quad 58$

Interview transcription equipment $\quad 58$ 
Procedures $\quad 58$

Recruitment of participants $\quad 58$

Data collection $\quad 59$

$\begin{array}{ll}\text { Data analysis } & 60\end{array}$

$\begin{array}{ll}\text { Trustworthiness } & 60\end{array}$

Summary $\quad 62$

$\begin{array}{ll}\text { References } & 63\end{array}$

APPENDIX A: HUMAN SUBJECTS-INSTITUTIONAL REVIEW BOARD APPROVAL 71

APPENDIX B: RECRUITMENT EMAIL TO CAUSE-BASED TRAININGPROGRAM STAFF 72

APPENDIX C: RECRUITMENT MESSAGE TO PROSPECTIVE PARTICIPANTS

73

APPENDIX D: AGREEMENT TO PARTICIPATE IN RESEARCH

APPENDIX E: PARTICIPANT CONTACT INFORMATION AND

BACKGROUND QUESTIONNAIRE 76

APPENDIX F: INTERVIEW GUIDE

APPENDIX G: REFLEXIVE JOURNAL SAMPLE PAGES 80

APPENDIX H: MANUSCRIPT GUIDELINES FOR JOURNAL OF SPORT

BEHAVIOR

85 
Chapter 1

\section{INTRODUCTION}

In the late 1980s a new philanthropic paradigm emerged in the United States, that of the cause-based training program (King, 2006). These programs combined charitable fundraising with endurance-sport fitness training (King, 2006). Participants in such programs, in return for raising a predetermined amount of funds, were coached and trained to complete a specific endurance sport event such as a marathon (Havenar \& Lochbaum, 2007). The Leukemia \& Lymphoma Society pioneered this model with its Team in Training program (Team in Training, 2009). The model was so successful that it was quickly adopted by other for-profit and not-for-profit organizations, particularly those with missions to fight specific diseases (King, 2006; Nettleton \& Hardey, 2006). One example was the now-nonexistent, for-profit Pallotta TeamWorks AIDSRides, held in various locations across the United States (King, 2006). Three more current examples include two series of fundraising walks for breast cancer, the Avon Walk for Breast Cancer (Edwards, 2006), and the Susan G. Komen Breast Cancer 3-Day (King, 2006), also held in various U.S. locations; and the still-thriving Team in Training program, which has now expanded worldwide.

Cause-based training programs frequently imply and/or directly claim that the cause provides a highly effective motivation to exercise. For example, the Team in Training website (Team in Training, 2009) displays this unattributed quote: “Training’s tough. But chemo’s a whole lot tougher. It was the most worthwhile thing I ever did.” These words imply that the anonymous speaker found the cause to be a sufficient source 
of motivation, perhaps even of a sense of "worth," to accept the physical challenges. Such implied and/or stated claims may be a factor in the success of these programs. However, despite the growing popularity of these programs (King, 2006; Nettleton \& Hardey, 2006), little research has examined such claims. Therefore, the purpose of this study was to qualitatively research the relationship between a charitable cause and the motivation to train consistently.

Motivation has been researched extensively in the fields of sport and exercise psychology (Biddle, 1999; Dishman, 2001; Dishman \& Sallis, 1994; Summers, Sargent, Levey, \& Murray, 1982; Taylor \& Fox, 2005). Biddle (1999) noted that from 1985 to 1994, motivation was the dominant topic in two of the most prominent sport psychology journals. Multiple studies have examined the motivations of runners (Curtis \& McTeer, 1981a; Ogles, Masters, \& Richardson, 1995) and marathoners (Curtis \& McTeer, 1981b; Havenar \& Lochbaum, 2007; Masters \& Ogles, 1995; Ogles \& Masters, 2000, 2003; Summers, Machin, \& Sargent, 1983; Summers et al., 1982). Researchers have also studied other endurance sports such as triathlon and cycling (Hammermeister \& Burton, 2004). Furthermore, social psychology has examined the nature of altruism and volunteerism (Batson, 1991, 2006; Batson, Bolen, Cross, \& Neuringer-Benefiel, 1986). In this study, altruism is defined as the state of being motivated to increase the well-being of another, without necessarily incurring cost to the altruist herself or himself (Batson, 2006). Several studies have addressed motivations for philanthropic behavior, including the relationship between altruism and motivations for actual volunteerism in charitable causes (Bennett \& Kottasz, 2000; Brammer, Millington, \& Pavelin, 2006; Eveland and 
Crutchfield, 2007). However, as stated above, relatively little research has considered the relationship between altruism, such as a commitment to a charitable cause, and the motivation to train consistently for an endurance event (Havenar \& Lochbaum, 2007; King, 2006; Nettleton \& Hardey, 2006), or, as King (2006) stated, the motivation for “doing good by running well” (p. 29). Therefore, this study used previous research in both sport and exercise psychology and in social psychology to qualitatively examine the motivations of runners in a cause-based marathon-training program in order to analyze their ongoing motivation to train.

This thesis is presented in three chapters, including a proposed article for submission to the Journal of Sport Behavior. Chapter 1 is the thesis introduction. Chapter 2 is the manuscript of the proposed journal article. Chapter 3 provides extended support material for the article, including the entire revised contents of the original proposal for this thesis. Specifically, Chapter 3 includes the following chapters from the original proposal: Chapter 1, which introduces the thesis and explains the need for this study; Chapter 2, which is the review of literature; and Chapter 3, which describes the methods used in this study.

Chapter 2, the manuscript of the journal article, was written according to the submission guidelines for the Journal of Sport Behavior. These guidelines are included as Appendix H.

This chapter has summarized the contents presented in this journal-format study. The purpose of this study was to qualitatively research runners in a cause-based program 
in order to examine the relationship between the cause and the participants' motivations to train consistently. 
Chapter 2

JOURNAL ARTICLE 


\title{
A Qualitative Study of the Motivations of Runners in a Cause-Based Marathon-Training Program
}

\author{
Karin A. Jeffery \\ San José State University
}

In the late 1980s, the nonprofit sector in the United States introduced a new philanthropic paradigm, the cause-based fundraising endurance-training program. Participants in such programs raise funds for a charitable cause and, in return, are coached to complete a marathon or other endurance event (Havenar \& Lochbaum, 2007). Cause-based training programs frequently use recruitment messages implying that the cause provides a guaranteed motivation to exercise. However, little research has examined this assumption. Therefore, the purpose of this study was to qualitatively research runners in a cause-based marathon-training program in order to analyze their motivations to train consistently. Results suggested that the connection with the cause became a powerful motivating factor to train as the program progressed, even for participants who started with little or no such connection. One reason for this change was that several of the marathon trainees were themselves leukemia or lymphoma survivors. Thus the study participants trained with runners who not only represented the cause, but literally embodied it. A second reason was that the team workout structure allowed all runners to interact several times per workout, regardless of speed or ability level. Thus every participant had the opportunity to develop direct personal relationships with teammates who were survivors. Almost all participants reported that these factors substantially increased their own motivation to train. These results may be important not only for cause-based training programs, but also for interventions to enhance exercise motivation in general.

Address Correspondence to: Karin A. Jeffery, Department of Kinesiology, San José State University, One Washington Square, San José, CA 95192-0054, Phone: 650799-8371, E-mail: karin.jeffery@sjsu.edu. 
In the late 1980s, the nonprofit sector in the United States introduced a new philanthropic paradigm by combining charitable fundraising with endurance-sport fitness training (King, 2006). Participants in cause-based training programs commit to raise a predetermined amount of funds and, in return, are coached and trained to complete a specific endurance sport event such as a marathon (Havenar \& Lochbaum, 2007). The first program of this type was the Leukemia \& [sic] Lymphoma Society's Team in Training program (Team in Training, 2009). The model proved so successful that it was quickly adopted by other organizations, both for-profit and not-for-profit, particularly those with missions to fight specific diseases (King, 2006; Nettleton \& Hardey, 2006). A for-profit example was the Pallotta TeamWorks AIDSRides, held in various locations in the United States until Pallotta TeamWorks ceased operations in 2002 (King, 2006). More contemporary examples include two series of fundraising walks for breast cancer: the Avon Walk for Breast Cancer (Edwards, 2006) and the Susan G. Komen Breast Cancer 3-Day (King, 2006), both held in various locations around the United States.

One reason for the success of cause-based training programs may be their claims, both implied and stated, that the cause provides a highly effective motivation to exercise. For example, the Team in Training website displays this unattributed quote: “Training's tough. But chemo's a whole lot tougher. It was the most worthwhile thing I ever did" (Team in Training, 2009). These words imply that the anonymous speaker found the cause a sufficient source of motivation, perhaps even of a sense of "worth," to accept the physical challenges. However, despite the growing popularity of these programs (King, 2006; Nettleton \& Hardey, 2006), little research exists on the relationship between the charitable cause and the motivation to train consistently. Therefore, the purpose of this study was to qualitatively examine this relationship.

Motivation has been researched extensively in sport and exercise psychology (Biddle, 1999; Dishman, 2001; Dishman \& Sallis, 1994; Li, 1999; Summers, Sargent, Levey, \& Murray, 1982; Taylor \& Fox, 2005; Wininger, 2007). In fact Biddle (1999) noted that motivation was the dominant topic in two major sport psychology journals from 1985 to 1994. Numerous studies have examined the motivations of runners (Curtis \& McTeer, 1981a; Ogles, Masters, \& Richardson, 1995) and marathoners (Curtis \& McTeer, 1981b; Havenar \& Lochbaum, 2007; Masters \& Ogles, 1995; Ogles \& Masters, 2000, 2003; Summers, Machin, \& Sargent, 1983; Summers et al., 1982). Researchers have also studied other endurance sports such as triathlon and cycling (Hammermeister \& Burton, 2004). In addition, social psychology has closely examined the nature of altruism and volunteerism (Batson, 1991; Batson, Bolen, Cross, \& Neuringer-Benefiel, 1986) and the relationship between them (Bennett \& Kottasz, 2000; Brammer, Millington, \& Pavelin, 2006; Eveland and Crutchfield, 2007). However, as stated above, relatively little research has investigated the relationship between altruism, such as a commitment to a charitable cause, and the motivation to train consistently for an endurance event (Havenar \& Lochbaum, 2007; King, 2006; Nettleton \& Hardey, 2006), or, as King (2006) stated, the motivation for “doing good by running well” (p. 29). Therefore, this study drew on research in sport and exercise psychology as well as in social psychology to qualitatively examine the motivations of runners in a cause-based marathon-training program. 


\section{Motivation in Exercise and Running}

Several researchers have examined the motivational and amotivational factors related to consistent physical activity (Dishman, 2001; Dishman \& Sallis, 1994; Gill, 1987; Li, 1999; Wininger, 2007; Wright, Ding, \& Li, 2005). Dishman (2001) identified several issues hindering research in this area, including a tendency to focus more on exercise adoption than on adherence. He also stated that although motivation is often described in terms of “direction, intensity, and persistence” (p. 281), exercise motivation research typically addresses only one of these aspects, direction.

Li (1999) developed the Exercise Motivation Scale (EMS) to assess all aspects of motivation more effectively and, also, to do so in the exercise context rather than the sport context (Vallerand, Deci \& Ryan, 1987). His initial results with the EMS, which involved male and female college undergraduates, suggested that consistent exercisers were more intrinsically motivated than sporadic exercisers (Li, 1999). In another study using a more multidimensional approach to motivation, Wright, Ding, and Li (2005) suggested that adolescents were more motivated to exercise if they had higher perceptions of their physical ability, that is, of their physical self-efficacy (Bandura, 1997). That is, interventions to help adolescents increase self-efficacy might also help motivate them to be more physically active (Wright et al., 2005) even if such interventions did not directly address the direction aspect of motivation. Gill (1987) encouraged an even more multidimensional approach to exercise motivation. The author stated that applied sport psychology could benefit from incorporating more social psychological perspectives, because exercise behavior occurred in social contexts (1987). This approach was supported by the present study, in which interpersonal interaction emerged as a strong contributor to intrinsic motivation, as discussed below.

Starting with Morgan and Pollock’s (1997) groundbreaking study on cognitive strategies in marathoners, extensive research has focused on runners in general (Butryn \& Furst, 2003; Goode \& Roth, 2003; Mallett \& Hanrahan, 2004; Schilling \& Hayashi, 2001) and on marathoners in particular (Barrell, Chamberlain, Evans, Holt, \& Mackean, 1989; Curtis \& McTeer, 1981a, 1981b; LaCaille, Masters, \& Heath, 2004; Masters \& Ogles, 1995; Nettleton \& Hardey, 2006; Schomer, 1990; Schomer \& Connolly, 2002; Summers, Sargent, Levey, \& Murray, 1982; Summers, Machin, \& Sargent, 1983). Summers et al. (1983) surveyed 459 recreational marathoners, including both first timers and experienced marathoners. Goal achievement, including personal challenge and a sense of accomplishment, emerged as one of the main motivating factors. However, Summers et al. (1982) speculated that the marathon's increasing popularity stemmed from the inherent opportunities to meet a wide range of other goals as well, such as social recognition and self-fulfillment. Summers et al. (1982) also suggested that as runners aged, their motivations and goals changed, becoming more related to physical health.

Masters, Ogles, and Jolton (1993) developed the Motivations of Marathoners Scales (MOMS) to provide a standard psychometric scale with which to quantify research on the motivations of marathon runners. The MOMS measures motivation across nine scales including overall health orientation, weight concerns, social concerns, and personal 
goal achievement. Preliminary findings with the MOMS were consistent with those of Summers, Machin, and Sargent (1983). For example, the MOMS suggested that runners in their 20s were primarily motivated by personal goal achievement, whereas runners in their 50s and over were more motivated by factors involving general health. In terms of experience level, the MOMS indicated that first-time marathoners were more motivated by personal goal achievement than were more experienced marathoners (Masters et al., 1993).

Several studies have specifically examined the motivations of recreational runners training for their first marathon (Havenar \& Lochbaum, 2007; Scholz, Nagy, Shüz, \& Ziegelman, 2008; Summers, Sargent, Levey, \& Murray, 1982). Summers et al. (1982) surveyed 363 such runners, of whom a significant percentage reported goal achievement as their main motivation, a category which included both personal challenge and the sense of achievement (Summers et al., 1982). Scholz et al. (2008) also examined motivation in 30 runners training for their first marathon. The results suggested that increasing levels of self-efficacy (Bandura, 1997) and positive outcome expectancies were positively correlated with a successful marathon outcome.

Havenar and Lochbaum (2007) used the MOMS to examine the motivations of runners training for their first marathon. Their study was unique because although it did not specifically examine motivation in the cause-based training context, all participants were recruited from cause-based training programs. The authors suggested that this may have been an unexpectedly significant factor in the results. For example, program dropouts were more focused on social and weight-related motivational concerns than were finishers. The authors (2007) suggested that these dropouts might have met their social goals through fundraising alone and thus had no need to complete the physical components of the program.

\section{Altruism, Charitable Volunteerism, and Cause-Related Physical Activity}

Considerable research in social psychology has examined motivational factors related to altruistic behavior and charitable volunteerism (Batson, 1991; Batson, Bolen, Cross, \& Neuringer-Benefiel, 1986; Bennett \& Kottasz, 2000; Eveland \& Crutchfield, 2007; Youn \& Kim, 2008). Batson (1991) and Batson et al. (1986) suggested that individuals tended to help others for whom they felt empathy, because they then experienced intrinsically rewarding positive feelings. When empathy was not present, altruistic behavior was more likely to be extrinsically motivated, such as by the prospect of material or social rewards (Batson, 1991; Batson et al., 1986). In cause-based training programs, material rewards can include gear and clothing that bears the charitable organization's logo, while social rewards can include weight loss and the subsequent compliments from others. However, studies by McAuley and Blissmer (2000) and Raglin (2001) imply that such extrinsic rewards are more significant in exercise adoption than in adherence. This implication supports Li's (1999) results indicating that consistent exercisers are more intrinsically motivated than non-adherers. It also supports Havenar and Lochbaum's (2007) investigation of the motivational factors of adherers versus dropouts in cause-based marathon-training programs. The authors (2007) suggested that 
the dropouts were more likely to have specified primarily extrinsic motivations for joining, such as social recognition and weight loss, than the adherers.

Therefore, the present study addressed the motivational factors not only to join a cause-based endurance-training program, but to adhere to the training schedule and complete the event. The purpose of this study was to examine the relationship between a charitable cause and the participants' motivations to train consistently.

\section{Method}

\section{Participants}

Thirteen runners (six females and seven males) participated in this study, all of whom had successfully run their first marathon as members of the same cause-based training program. The number of participants was determined when data saturation was reached (Seidman, 1998). Ten of the participants ran their first marathon within a year of this study, while the other three ran their first marathon more than one year prior to the study. All participants were San Francisco Bay Area residents recruited through a local office of the cause-based program, and all were at least 18 years old. The participants identified themselves as Chinese American, Latino/Latina, Native American, Philipino/Philipina, and White. All had similar socioeconomic backgrounds and were professionals in their respective fields, although two were unemployed at the time of the interviews.

\section{Interview Technique}

The researcher interviewed each participant individually and recorded the interviews with the participant's knowledge and consent. The average time per interview was one hour. The researcher designed a semi-structured interview guide based on previous qualitative research (Carter \& Bloom, 2009; Mallett \& Hanrahan, 2004). The interview guide included questions and follow-up probes about training-related motivations, perceptions, and experiences in the program. Thick and rich description was used to capture participant perceptions and experiences in as much detail as possible and to contextualize the results (Atkinson, 2000; Dale, 1996, 2000; Jackson, 1995, 1996; Sparkes, 2002).

\section{Data Analysis}

All interviews were transcribed verbatim by the researcher. Each transcription was checked for accuracy and reread to establish researcher familiarity with the material. The transcribed interviews were then inductively analyzed and coded for themes according to the procedures recommended by Côte, Salmela, Baria, and Russell (1993), Gratton and Jones (2004), and Jackson (1995). The data was first sorted into raw data themes, then into higher order themes, and finally into general categories that were used to further analyze the participants' training-related motivations, perceptions, and experiences. Throughout this process the researcher followed established guidelines for qualitative research (Andrews, Mason, \& Silk, 2005; Dale, 1996, 2000; Glesne, 2006; Sparkes, 1998, 2002). 


\section{Trustworthiness}

The researcher used several procedures to establish data trustworthiness. For example, a sport studies professional with extensive experience in qualitative research methods provided ongoing feedback in every phase of this study. Before the start of data collection, this professional evaluated the original study proposal, methodology, and interview guide (Culver, Gilbert, \& Trudel, 2003). During data collection, two sessions were held to review the transcribed interviews and to provide feedback on the researcher's interview technique. Finally, after data collection was complete, another session was held to review the researcher's thematic interpretation of the results (Sparkes, 1998).

In addition, before the start of data collection, the researcher participated in a bracketing interview with the aforementioned sport studies professional (Dale, 1996, 2000). The researcher transcribed the interview verbatim, and the transcription was discussed during a peer-review session transcription (Culver, Gilbert, \& Trudel, 2003). This process allowed the researcher to experience the actual interview process, evaluate and improve the interview guide, and identify any personal biases that might affect the interpretation of the data (Dale, 1996, 2000).

The researcher also kept a reflexive journal throughout the study. This journal served as both a "methodological log” (Dale, 1996, p. 24) and a record of the researcher's thoughts and feelings during data collection and analysis. This journal helped the researcher identify and maintain awareness of her attitudes and biases throughout the research process (Maxwell, 2005).

Member checking (Maxwell, 2005) was used to allow participants to verify the accuracy both of the interview data gathered and of the researcher's interpretation of the data. Member checking also helped the researcher maintain awareness of any personal biases that might have affected the recording and analysis of participant data (Maxwell, 2005). Six participants responded to the researcher, all of whom confirmed that the transcripts were accurate.

Finally, as recommended by Sparkes (1998), the data analysis was peer-reviewed by an experienced qualitative researcher. Two sessions were held to review the researcher's analysis of raw data themes, higher order themes, and categories.

\section{Results}

\section{Thematic Analysis}

Analysis of the interview data produced a total of 65 raw data themes. These raw data themes were combined into 19 higher order themes, then into three main general categories and four supporting categories (Côte, Salmela, Baria, \& Russell, 1993). The three main categories were the connection with the cause, improved fitness and athleticism, and training support from within the training group. The four supporting categories were social support from within the training group (unrelated to the training aspect), personal growth, fundraising, and the response from family, friends, and others external to the training group. The following sections discuss these seven categories with 
particular emphasis on the three main categories.

\section{Connection with the Cause}

The connection with the cause was one of the two categories to yield the most data; the other category was improved fitness and/or athleticism. Twelve of the 13 participants stated that over the course of the program, they became more deeply connected with the cause, which in turn became an increasingly powerful factor in their motivation to train. Their growing sense of connection appeared unrelated to their sense of connection when they first joined the program. Six of these 12 participants joined the program with little or no sense of connection. Lisa, who had been injured in an automobile accident, decided to run a marathon to prove to herself that she had recovered. Her goal was consistent with the motivational factors identified by Summers, Sargent, Levey, and Murray (1982) related to maintaining or regaining mastery of one's own body. Andrea, Carolyn, Katie, Sean, and Victor wanted to improve their endurance sport skills, although all five wished to do so in a charitable context. Katie stated that when she joined, “The cause was secondary, which sounds so bad. I didn't have a personal connection with it.” The other six participants all had a prior connection with the cause, but each participant explicitly stated that this was not the primary reason for joining the program. Geoff had lost his older brother to leukemia several years previously, but his main goal was to run a marathon by age 40. Michelle, herself a lymphoma survivor, had also hoped to run a marathon by age 40, but had not done so. She now wanted to meet her goal before her next birthday. The other four participants had had close relationships with survivors or victims of leukemia or lymphoma and/or with oncology professionals, but again, these relationships were not their reasons for joining the program. Three joined to achieve personal goals of taking on a new physical challenge and/or gaining a sense of achievement. This was consistent with previous research into the motivations of runners to attempt the marathon distance (Curtis \& McTeer, 1981a, 1981b). The fourth, Erin, joined as a way to cope with her depression over being unemployed.

All 12 of these participants stated that their increased sense of connection also increased their motivation to train. Eleven reported that this occurred mainly because some of other members of their training group were themselves cancer survivors who were training for the same marathon. That is, these eleven participants literally trained side by side with runners who had survived leukemia or lymphoma, who embodied as well as represented the cause, and who also endured the rigors of marathon training. As Katie put it:

It was just amazing, what they could do and how much they, how strong they were. And some of them, it had been a number of years so I understand, but then someone could be out of a hospital bed and then running on track night. Yeah, I was just really surprised at the level of fitness and endurance, and how these were just regular people who had a disease and are dealing with it. And are still extremely active, obviously, to be with us. So it was very encouraging.

Significantly, even Michelle, herself a lymphoma survivor, said she was inspired by 
another survivor, Mark, who faced a high probability that his cancer would return. As she put it, "it's quite possible that the dollars [the participants] have all contributed, maybe this season, are going to go toward the cure, so that if his cancer comes back the doctors can say, 'We've found a treatment.' That kind of thing is motivating to me.” Dave, in turn, stated that running with Michelle inspired him to keep up his own training. Even after he became injured and could not run without considerable pain, he maintained that if she could complete the workouts, so could he.

Several participants also reported other ways in which their growing connection with the cause became a motivating factor in their training. Sean's marathon workouts were frequently attended by the parents of a young child who had leukemia. During these workouts Sean was highly motivated by hearing about the child's treatment history and the entire family's experience. Similarly, Andrea learned mid-program that her mother's friend, a young leukemia survivor with a family, had relapsed. She dedicated both her training and her marathon to this family. These participants' observations implied that they not only felt empathy for cancer patients and survivors, as suggested by research in social psychology (Batson, 1991; Batson, Bolen, Cross, \& NeuringerBenefiel, 1986); but that they also believed they could positively affect the lives of survivors. This was consistent with Wright, Ding, and Li's (2005) suggestion that increased self-efficacy (Bandura, 1997) might help motivate individuals to be more physically active.

The connection with the cause also emerged as an intrinsic motivating factor to complete during the marathon itself. Nine participants reported that despite extreme fatigue, they ran faster whenever spectators cheered for the charitable organization. Five of these participants, Dave, Andrea, Erin, Ron, Katie, experienced extreme discomfort and/or pain during the marathon. Each of them stated that their strong sense of connection with the cause motivated them to finish the marathon regardless.

Brandon was the one participant who did not experience a deepening connection with the cause during the program. He did not attend several group workouts and therefore had fewer opportunities to interact with other members of the training group, including those who were also cancer survivors. His motivations and experiences are discussed in more detail in a later section.

The above results support the claim by cause-based training programs that the sense of connection becomes a powerful motivating factor to train. The participants' deepening sense of connection not only supported their original intrinsic motivations, but represented a motivational evolution that increased the overall meaningfulness of their cause-based training program experience (Vallerand, Pelletier, \& Koestner, 2008).

\section{Improved Fitness and Athleticism}

Improved fitness and athleticism was the second main thematic category to emerge in this study. As described above, 12 of the 13 participants, including those having prior connections with the cause, joined the program primarily to reach personal achievement goals such as running farther and faster. The one exception was Erin, who joined to conquer her depression over being unemployed. Sean was already a multi-sport endurance athlete and felt that the marathon was the logical next step to improve his 
running ability. His motivation to run longer distances was consistent with that of runners in previous marathon research (Curtis and McTeer, 1981a, 1981b). Brandon and Katie both sought hard workouts that would challenge them physically. Carolyn, Geoff, and Jake wanted to improve their running gait and technique as well as their distance and speed. These results were consistent with Schomer's findings (1990) that self-described "serious" runners were motivated not only by getting faster, but by improving the overall quality of their running.

Regardless of their initial reasons for joining, all thirteen participants became more motivated to train as their speed and fitness increased. For example, both Dave and Jake, the two self-described "big guys" in this study, unexpectedly found that they were fast enough to keep up with many of their fellow runners. As Dave described one of his workouts,

And this guy, who I thought was pretty quick too, said, "You're fast. You know, I could not keep up with you. You were my motivation to try to do better." I said, “Me?” He said, “Yeah, didn’t you see?” I guess I had left everybody. . . Other participants also reported feeling more motivated after discovering that they were fast runners. Like Dave, Erin was surprised to find that she was faster than many others in the training group. She stated that this motivated her to be even more competitive in her running. Michelle also reported becoming more competitive as the program continued. Lisa and Carolyn both expressed the wish to have had even more opportunities for competition, such as pushup contests during the strength-building segments of the Tuesday track workouts.

Finally, several participants mentioned the motivation of having a proven, effective training schedule. Michelle, Brandon, and Sean had all heard that the program training schedule increased mileage at a safe rate and thus reduced the risk of injury. Carolyn confirmed this by reporting that, to prepare herself for the start of the program, she followed another training schedule on her own for two weeks, slightly injuring herself in the process. Once she started on the official program training schedule, she had no further problems.

The predominance of initial achievement motives, as described above, supported Havenar \& Lochbaum's (2007) findings that successful first-time marathoners rated achievement motives more highly on the MOMS than did program dropouts. Also consistent with Havenar and Lochbaum (2007) was the fact that none of the participants joined the program specifically to lose weight, although three of them mentioned weight loss as a concurrent benefit.

\section{Training Support from within the Training Group}

Training support within the program was the third main thematic category to emerge from the data. As stated, 12 of the 13 participants, with the exception of Erin, joined the cause-based training program primarily because of achievement goals.

However, except for Brandon and Carolyn, all participants reported feeling increasingly connected with other members of the training group as the program progressed. As a result, they actively helped each other to remain motivated to train by providing support and encouragement when necessary. 
For example, Michelle stated that despite various discouraging factors, she remained motivated to attend workouts in order to support the other runners:

Especially this past winter, it seemed like [laughs] it's going to rain, or . . . you know, it's cold. Just being cold, not even raining, oh, maybe I'll skip it. And it was like no, these people are going to be there and I need to go, to kind of support the team and be another person.

By contrast, Andrea stated that she was motivated to attend workouts because of the support she received:

You never got in trouble if you didn’t go, but your friends kept you accountable. So it's like, "Oh, where were you last Tuesday?" or "How come you didn't run Saturday?” or “What's your excuse this time?” So I don't know, that just kind of keeps you going.

These results suggested that within-group support became a primary motivating factor for almost all participants to train consistently. Brandon, the exception, had previously had a positive experience with a similar cause-based training program, making several good friends who trained together and challenged each other. Within a few weeks of joining the marathon program in the present study, he determined that it would not replicate his previous experience. Thus he chose not to attend several group workouts and instead trained on his own or participated in other athletic activities. Although he did complete the training program and the marathon, his experience supports Havenar and Lochbaum's (2007) suggestion that runners who joined such programs because of social goals were less likely to have a satisfactory experience than those who joined because of achievement goals.

\section{Social Support from within the Training Group (Unrelated to the Training Aspect)}

The social aspects of the program, in terms of factors unrelated to training, was the first of four supporting categories to emerge in this study. Only three of the 13 participants, Brandon, Erin, and Ron, identified social motives as a primary reason for joining a cause-based marathon-training program (Masters, Ogles, \& Jolton, 1993). As the program progressed, Brandon and Erin both reported that social factors became less important. As described above, Brandon did not develop close relationships within the group and trained extensively on his own. Erin did in fact develop several close friendships, but was far more motivated by finding that she was a competitively fast runner than by the social interactions within the training group. Ron was the only participant who both joined for primarily social reasons and who continued to enjoy the social interaction aspects of the program throughout. He joined the program after it had already begun because several of his friends had already joined and encouraged him to do the same.

The remaining 10 participants, who had not specified social factors as their reasons for joining the program, expressed a range of responses to this aspect. Some, like Andrea, came to welcome it; in fact for her it became one of the most motivating aspects of the entire program. She readily admitted that not only did she not enjoy the activity of running, but that she actually "hated" it. However, she made several good friends during the training program. This kept her motivated to attend group workouts because she and 
her friends would chat and dissociate throughout the runs:

If I ever do go run by myself - I was at track a couple of weeks ago . . . I was running by myself and like, this is the most ridiculous thing, why am I even doing this, I hate it. And then when we actually did our workout I was running with my friends, I was like, OK, this is a little bit better. And they all rely on me to tell them stories [laughs].

While Geoff did not actively hate running, he often found it physically challenging. Like Andrea, he enjoyed conversing with his fellow runners while running because it prevented him from noticing the running itself. The comments from these two participants are consistent with previous research suggesting that runners who describe themselves as only moderately serious are also more likely to dissociate while running (Masters \& Ogles, 1995, 1998; Schomer, 1990). That is, they prefer to focus on external factors such as conversation, rather than attend to their running technique and physical sensations. By contrast, other participants did prefer to focus on their running. For example, Carolyn was very motivated to improve the quality of her running. She therefore made a conscious effort to socialize as little as possible during workouts because it reduced her ability to focus on her technique. This was also consistent with previous research that self-described serious runners were more likely to associate than dissociate (Masters and Ogles, 1995, 1998; Schomer, 1990). Partly because Carolyn did not interact much with other group members during workouts, she did not develop any close relationships during the program. She expressed mild regret over this, but felt that the improvements in her running had been worth it.

\section{Personal Growth}

Personal growth was the second supporting category to emerge in this study. The three participants who mentioned it as being motivating described it differently. For example, as stated above, Lisa joined the program to prove to herself that she had recovered from the injuries she had sustained in the automobile accident. Dave had started running several months before the program started. He was both amazed and delighted, not only with the physiological benefits, but with the evolution of his selfimage from "a lump of clay on the couch" to a runner. He was excited to see where this evolution might lead. Jake had run in several races of three to five miles, but when he joined the program, he was overweight and had also been diagnosed with social anxiety disorder. He viewed his marathon run training effort as analogous to summiting one of the world's highest mountains: "I remember thinking, this is our expedition. . . We're all going to travel somewhere really far away and climb a mountain really high .... and that's gonna be cool."

Dave and Jake reported that personal growth became an even stronger motivating factor as the program continued. Both described their growing satisfaction at seeing that "big guys could do this," that is, could train for and complete a marathon run. This discovery enhanced their sense of life meaning in general (Masters, Ogles, \& Jolton, 1993; Vallerand, Pelletier, \& Koestner, 2008) by showing them that their actual abilities

exceeded their own perceived limits. Jake continued to see the program as an expedition to summit an 8000-meter peak. He noted that he grew more motivated as the season 
progressed, "because it felt more real, it felt more doable." On the evening before the marathon, although nervous, he was also very excited because the expedition was finally about to happen.

For both Jake and Lisa, the marathon run itself was also transformative. Lisa described it as living an entire lifetime in one event, because of the broad range of emotions she experienced, from very negative to very positive. She gained a great deal of self-awareness from this experience, particularly from her successful efforts to prevent doubts and anxieties from interfering with her running. Jake stated that crossing his first marathon finish line was literally life-changing. "The world was a different place after that."

\section{Fundraising}

Fundraising was the third supporting category to emerge from the data. All participants in the present study were required to either raise or donate approximately $\$ 2500$ to the charitable cause in order to remain in the program. This requirement evoked a range of responses from amotivation to neutrality to motivation. For Michelle, the prospect of fundraising was extremely amotivating. Although she herself was a cancer survivor, she felt unable to ask others for donations. In fact, one of her reasons for joining the program was that a relative had also joined and had offered to fundraise for both of them. When this relative dropped out a few weeks later, Michelle seriously considered dropping out as well, although she ultimately chose to continue.

Seven participants expressed relative unconcern about fundraising. For example, Brandon did not attempt to start raising funds until the final third of the program. However, he was confident that he could raise the required amount and in fact did so relatively effortlessly. Ron, a program veteran, was equally confident and successful. Katie was equally confident and successful, despite having joined the program when it was already more than halfway over. Carolyn raised a portion of her funds by offering sports massage therapy sessions to potential donors. Although massage therapy was not her primary occupation, she stated that it was a useful skill for incentivizing potential donors.

Finally, two participants, Geoff and Andrea, found fundraising to be an actual motivating factor. Both reported that their fundraising became easier once they developed a deeper connection with the cause. They described their initial fundraising efforts as somewhat generic and superficial. Their growing friendships with teammates who were cancer survivors inspired them to revise and resubmit their first requests. Andrea's revision was so successful that she finished her fundraising less than halfway through the program and subsequently helped her teammates with their own fundraising efforts. She stated that her fundraising success motivated her to continue to train: It [running] sucked some days, honestly. Some miles were harder than others. But I don't know, you just keep going. You've already raised so much money, you've already committed to it, so you just have to follow through.

Her statement directly contradicts Havenar and Lochbaum's (2007) suggestion that individuals with primarily social goals drop out of such programs because they achieve their goals by fundraising rather than running. In the present study, Andrea was the 
participant who least enjoyed running and most enjoyed social interaction. Nevertheless, the funds she raised motivated her to continue rather than drop out.

Like Andrea, Geoff rewrote and re-sent his sponsorship request to reflect his growing personal connections both with the cause and with cancer survivors: "And then when I started getting those back, with messages written on them and donations, it just floored me. I was just amazed. And that was a huge, huge thing for me too.”

Finally, Victor was one of several participants who felt burdened by not completing his fundraising until the program was almost over. However, his final response to the fundraising requirement was to feel "overwhelmed" by how many funds he and his teammates raised, to the point that running the marathon became almost unimportant:

Just the good that, I guess, we did, or that was accomplished and everything, fundraising-wise. I mean that feeling alone was . . . I guess I didn't even really need to run the marathon after that. [Laughs] I'm good! [Laughs] After just that high of being able to accomplish, like, the fundraising minimum, get to that point, well, wow ...

To summarize, the fundraising component evoked a variety of responses from the study participants. However, since this study was delimited to individuals who had completed all components of the cause-based training program, all participants managed this requirement successfully.

\section{Response from Family, Friends, and Others External to the Training Group}

Nine participants reported that their family, friends, and coworkers supported their decision to join a cause-based marathon-training program. For example, Geoff's partner provided extensive assistance, both emotional and logistical:

Waking up cranky with sore feet, or coming back from a long run, and having to rely on him to pack my lunch and make dinner and do all this other stuff while I'm sitting there stretching [laughs]. So it's a huge commitment on his part too, to support me going through this.

Dave's wife not only encouraged him to join the program but temporarily took over many of his responsibilities for raising their children, even though she also worked full-time.

Similarly, Erin's parents encouraged her to join and also helped with her fundraising after she discovered that most of her own cohort could not afford to sponsor her.

Carolyn, Lisa, and Michelle received mixed responses from family and friends. Carolyn reported that several friends asked why she had accepted such a large fundraising commitment rather than simply joining a running club. However, none of them questioned her commitment to the cause itself. Some of Lisa's relatives expressed concern that the training would hinder rather than help her to recover from her automobile accident. Michelle reported an unfavorable response from a family member who did not believe that there was a rational reason to run a marathon distance.

Of the 13 study participants, Sean received the most negative responses from family and friends. He interpreted this as being partially related to Chinese-American cultural issues:

Interviewer: Your mom was never happy with your running and cycling? 
Sean: Yeah. It was always, this, “it's un-Chinese.” ... None of my aunts, and my mom, even know how to ride a bike. It was something about in China, where they just don't ride bikes.

Interviewer: Because it's a reflection on your socioeconomic status, or something like that?

Sean: I don't know. I'm not sure about that. But they don't even know how to ride a bike ... Y Yeah, my mom, when I told her I'd signed up for this it's like, "How many miles is it?” “26.2.” "Why do you have to run it? Can’t you just drive it?” And I'd be like, ohhhh ... . [Sighs]

Sean also stated that most of his family did not understand why he chose to become involved in a philanthropic activity for which, from their perspective, he received no extrinsic reward:

It was one of those things where I say, unfortunately, I don't know if it's more with Asians or something like that, they're not big into, for whatever reason, just kind of like giving stuff away. It's kind of like, "What's in it for me?" So it would annoy me that, they have these things in San Francisco, where, for scholarships or whatever. So like my uncle's last name is Wong. So they'd have this Wong family party where everybody whose last name is Wong, you paid like 25 bucks a person, have this dinner, and then like the money goes to whatever, some charity or something like that. . . But, you know, see, they got dinner out of it. They weren't getting anything out of me.

Sean's observations were consistent with previous research suggesting that when empathy was not present, altruistic behavior was more likely to be motivated by the prospect of an extrinsic reward, either social and/or material (Batson, 1991; Batson, Bolen, Cross, \& Neuringer-Benefiel, 1986). Sean's other responses during the interview suggested that his genuine empathy for cancer patients motivated him to raise funds for cancer research. However, his family did not share his perspective.

\section{Discussion}

The purpose of this study was to qualitatively research the motivations of runners in a cause-based marathon-training program, particularly in terms of the relationship between the cause and the motivation to train consistently. The thematic data analysis yielded three main categories: the connection with the cause, improved fitness and athleticism, and training support from within the training group. The data analysis also produced four supporting categories: social support from within the training group (unrelated to the specific training aspect), personal growth, fundraising, and the response from members of the participant's social network who were external to the training group.

The first category, connection with the cause, was the most relevant to the present study. None of the 13 participants specified that the cause was their main motivating factor for joining the program; in fact, six specifically reported having little or no prior connection. Even Michelle, who had survived the specific cancer which the charitable organization was dedicated to eradicating, stated that this was not her reason for joining. 
Nevertheless, as the season progressed, these 12 participants experienced a growing sense of connection with the cause, which motivated them to follow their training schedule and complete the marathon. All 12 stated that the cause motivated them to attend group workouts despite external amotivating factors, such as bad weather, or internal amotivating factors, such as physical and/or psychological fatigue. These data appeared to support the claim frequently made by cause-based training programs that the cause becomes a motivating factor to train consistently.

These data have potential significance for both cause-based training programs and exercise adherence in general. First, the data suggest that the motivational factors in exercise adoption may be less important than the motivational factors to adhere to an exercise program. In this study, as stated above, the participants reported a broad range of previous connections with the cause, ranging from "survivor" to "none."

Nevertheless, 12 of these 13 participants became more motivated to train after developing relationships with training group members who literally embodied the cause, rather than simply representing it. These data suggest that the motivation to adopt a physical activity program may be less significant than subsequently developed motivations to continue with it. That is, if it is possible to identify the most significant motivational factors contributing to the success of cause-based endurance-training programs, it may also be possible to extrapolate some of these strategies to interventions for increasing physical activity levels among the general population. In addition, such strategies may prove effective not only in achieving a specific goal, such as running a marathon, but in accomplishing permanent lifestyle changes incorporating regular physical activity.

\section{Study Limitations and Future Directions}

This study suggests multiple opportunities for future research. Because all participants were recruited from a single cause-based training program, the results may not generalize to other cause-based training programs, of which a wide variety exists. Future research might compare motivational functions across several such programs. In addition, future studies might consider dropouts and non-finishers as well as finishers. For example, research could investigate the role of socioeconomic status, since such programs typically require athletes to contribute the outstanding balance of whatever they do not raise.

Future research might also investigate the relationship between proximity (Weinberg \& Gould, 2007) and the sense of connection with the cause. As described above, the 13 participants in the present study had continuous opportunities to meet and bond with teammates who had survived cancer. Twelve of these participants reported that the resulting relationships became a primary factor in their motivation to train. These results may not generalize to programs in which participants have less direct contact with individuals who literally embody the charitable cause.

Finally, future research should consider the relationship between the motivational aspects of the cause and the specific sport (Schilling \& Hayashi, 2001). In the present study, as described above in relation to proximity, the workout structure provided frequent opportunities for teammate interaction, regardless of speed or running ability. 
This was the case even during the longest workouts, which involved 20-mile runs. Thus the workout structure promoted interactions and relationships with all teammates, including those who were cancer survivors. By contrast, cause-based endurance cycling training can involve rides of 80 miles or more and, for safety reasons, cyclists are often separated into groups of 10 or fewer. Thus it is possible that endurance cycling is less conducive to interaction throughout the entire team. Triathlon, which involves the three sports of swimming, cycling, and running, offers even more potential permutations of training activities that are more or less conducive to building relationships. Therefore, future research should also examine other endurance sports offered by cause-based training programs.

Finally, future studies should incorporate mixed research methods. For example, a follow-up to Havenar and Lochbaum's (2007) research could incorporate both qualitative analysis instruments such as the MOMS and qualitative analysis methodology.

In conclusion, the results of this study suggested that for athletes in a cause-based endurance-training program, participants with existing intrinsic motivations derived additional training motivation from their sense of empathy and connectedness with the based training programs and other populations.

\section{References}

Andrews, D. L., Mason, D. S., \& Silk, M. L. (2005). Qualitative methods in sports studies. New York: Berg.

Atkinson, M. (2000). Brother, can you spare a seat?: Developing recipes of knowledge in the ticket scalping subculture. Sociology of Sport Journal, 17, 151-170.

Bandura, A. (1997). Self-efficacy: The exercise of ontrol. W. H. Freeman and Company: New York.

Barrell, G., Chamberlain, A., Evans, J., Holt, T., \& Mackean, J. (1989). Ideology and commitment in family life: A case study of runners. Leisure Studies, 8, 249-262.

Batson, C. D. (1991). The altruism question: Toward a social-psychological answer. Hillsdale, NJ: Erlbaum.

Batson, C. (2006). SIT or STAND?. Psychological Inquiry, 17, 30-38. doi:10.1207/s15327965pli1701_02.

Batson, C. D., Bolen, M. A., Cross, J. A., \& Neuringer-Benefiel, H. E. (1986). Where is the altruism in the altruistic personality? Journal of Personality and Social Psychology, 50, 212-220.

Bennett, R., \& Kottasz, R. (2000). Advertisement style and the recruitment of charity volunteers. Journal of Nonprofit and Public Sector Marketing, 8, 45-63.

Biddle, S. J. H. (1999). Motivation and perceptions of control: Tracing its development and plotting its future in exercise and sport psychology. Journal of Sport and Exercise Psychology, 21, 1-23.

Brammer, S., Millington, A., \& Pavelin, S. (2006). Is philanthropy strategic?: An analysis of the management of charitable giving in large UK companies. Business Ethics: A European Review, 15, 234-245.

Butryn, T. M., \& Furst, D. M. (2003). The effects of park and urban settings on the moods 
and cognitive strategies of female runners. Journal of Sport Behavior, 26, 335-355.

Carter, A. D., \& Bloom, G. A. (2009). Coaching knowledge and success: Going beyond athletic experiences. Journal of Sport Behavior, 32, 419-437.

Côte, J., Salmela, J. H., Baria, A., \& Russell, S. J. (1993). Organizing and interpreting unstructured qualitative data. The Sport Psychologist, 7, 127-137.

Culver, D. M., Gilbert, W. D., \& Trudel, P. (2003. A decade of qualitative research in sport psychology journals: 1990-1999. The Sport Psychologist, 17, 1-15.

Curtis, J., \& McTeer, W. (1981a). Social influences in recruitment to marathoning. Review of Sports \& Leisure, 6, 58-82.

Curtis, S., \& McTeer, W. (1981b). Toward a sociology of marathoning. Journal of Sport Behavior, 4, 67-81.

Dale, G. A. (1996). Existential phenomenology: Emphasizing the experience of the athlete in sport psychology research. The Sport Psychologist, 10, 307-321.

Dale, G. A. (2000). Distractions and coping strategies of elite decathletes during their most memorable performances. The Sport Psychologist, 14, 17-41.

Dishman, R. (2001). The problem of exercise adherence: Fighting sloth in nations with market economies. Quest, 53, 27-294.

Dishman, R. K., \& Sallis, J. F. (1994). Determinants and interventions for physical activity and exercise. In C. Bouchard, R. J. Shepard, and T. Stephens (Eds.), Physical activity, fitness, and health (pp. 214-238), Champaign, IL: Human Kinetics.

Edwards, H. H. (2006). A rhetorical typology for studying the audience role in public relations communication: The Avon 3-Day disruption as exemplar. Journal of Communication, 56, 836-860.

Eveland, V. B., \& Crutchfield, T. N. (2007). Understanding why people do not give: Strategic funding concerns for AIDS-related nonprofits. International Journal of Nonprofit and Voluntary Sector Marketing, 12, 1-12.

Gill, D. L. (1987). The role of social psychology within applied sport psychology. AAASP Newsletter, 2, 9.

Glesne, C. (2006). Becoming Qualitative Researchers: An Introduction (3rd Ed.). Boston: Allyn \& Bacon.

Goode, K. T., \& Roth, D. L. (1993). Factor analysis of cognitions during running: Association with mood change. Journal of Sport \& Exercise Psychology, 15, 375389.,

Gratton, C., \& Jones, I. (2004). Research methods for sports studies. New York: Routledge.

Hammermeister, J., \& Burton, D. (2004). Gender differences in coping with endurance sport stress: Are men from Mars and women from Venus? Journal of Sport Behavior, 27, 148-164.

Havenar, J., \& Lochbaum, M. (2007). Differences in participation motives of first-time marathon finishers and pre-race dropouts. Journal of Sport Behavior, 30, 270-279.

Jackson, S. A. (1995). Factors influencing the occurrence of flow state in elite athletes. Journal of Applied Sport Psychology, 7, 138-166.

Jackson, S. A. (1996). Toward a conceptual understanding of the flow experience in elite athletes. Research Quarterly for Exercise and Sport, 67, 76-90.

King, S. (2006). Pink Ribbons, Inc. Minneapolis: University of Minnesota Press. 
Kretchmar, R. S. (2001). Duty, habit, and meaning: Different faces of adherence. Quest, 53, 318-325.

LaCaille, R. A., Masters, K. S., \& Heath, E. M. (2004). Effects of cognitive strategy and exercise setting on running performance, perceived exertion, affect, and satisfaction. Psychology of Sport \& Exercise, 5, 461-476.

$\mathrm{Li}, \mathrm{F}$. (1999). The exercise motivation scale: Its multifaceted structure and construct validity. Journal of Applied and Sport Psychology, 11, 97-115.

http://search.ebscohost.com.libaccess.sjlibrary.org, doi: 10.1080/10413209908402953

Mallett, C. J., \& Hanrahan, S. J. (2004). Elite athletes: Why does the 'fire' burn so brightly? Psychology of Sport and Exercise, 5, 183-200.

Masters, K., \& Ogles, B. (1995). An investigation of the different motivations of marathon runners with varying degrees of experience. Journal of Sport Behavior, 18, 69-79. Retrieved June 30, 2009, from PsycINFO database.

Masters, K. S., \& Ogles, B. M. (1998). The relations of cognitive strategies with injury, motivation, and performance among marathon runners: Results from two studies. Journal of Applied Sport Psychology, 10, 281-296. doi:10.1080/10413209808406394

Masters, K., S., Ogles, B. M., \& Jolton, J. A. (1993). The development of an instrument to measure motivation for marathon running: The Motivations of Marathoners Scales (MOMS). Research Quarterly for Exercise and Sport, 64, 134-143.

Maxwell, J. A. (2005). Validity: How might you be wrong? In J. A. Maxwell, Designing qualitative research: An interactive approach (2nd Ed.) (pp. 105-116). Thousand Oaks: Sage Publications, Inc.

McAuley, E., \& Blissmer, B. (2000). Self-efficacy determinants and consequences of physical activity. Exercise and Sport Sciences Reviews, 28, 85-88.

Morgan, W. P., \& Pollock, M. L. (1977). Psychological characterization of the elite distance runner. Annals of New York Academy of Sciences, 301, 382-404.

Nettleton, S., \& Hardey, M. (2006). Running away with health: The urban marathon and the construction of "charitable bodies." health [sic]: An Interdisciplinary Journal for the Social Study of Health, Illness and Medicine, 10, 441-460.

Ogles, B., \& Masters, K. (2000). Older vs. younger adult male marathon runners: Participative motives and training habits. Journal of Sport Behavior, 23, 130-143. Retrieved from PsycINFO database.

Ogles, B. M., \& Masters, K. S. (2003). A typology of marathon runners based on cluster analysis of motivations. Journal of Sport Behavior, 26, 170-180.

Ogles, B. M., Masters, K. S., and Richardson, S. A. (1995). Obligatory running and gender: An analysis of participative motives and training habits. International Journal of Sport Psychology, 26, 233-248.

Raglin, J. S. (2001). Factors in exercise adherence: Influence of spouse participation. Quest, $53,356-361$.

Schilling, T. A., \& Hayashi, C. T. (2001). Achievement motivation among high school basketball and cross-country athletes: A personal investment perspective. Journal of Applied Sport Psychology, 13, 103-128.

Scholz, U., Nagy, G., Shüz, B., and Ziegelman, J. P. (2008). The role of motivational and volitional factors for self-regulated running training: Associations on the between- 
and within-person levels. British Journal of Social Psychology, 47, 421-439.

Schomer, H. H. (1990). A cognitive strategy training programme for marathon runners: Ten case studies. South African Journal for Research in Sport, Physical Education \& Recreation, 13, 47-78.

Schomer, H., and Connolly, M. (2002). Cognitive strategies used by marathoners in each quartile of a training run. South African Journal for Research in Sport, Physical Education \& Recreation, 24, 87-99.

Seidman, I. (1998). Interviewing as qualitative research: A guide for researchers in education and the social sciences. New York: Teachers College Press.

Sparkes, A. C. (1998). Validity in qualitative inquiry and the problem of criteria: Implications for sport psychology. The Sport Psychologist, 12, 363-386.

Sparkes, A. C. (2002). Telling tales in sport and physical activity: A qualitative journey. Champaign, IL: Human Kinetics.

Summers, J. J., Machin, V. J., \& Sargent, G. I. (1983). Psychosocial factors related to marathon running. Journal of Sport Psychology, 5, 314-331.

Summers, J. J., Sargent, G. I., Levey, A., \& Murray, K. D. (1982). Middle-aged, non-elite marathon-runners: A profile. Perceptual and Motor Skills, 4, 963-969.

Taylor, A. H., \& Fox, K. R. (2005). Effectiveness of a primary care exercise referral intervention for changing physical self-perceptions over 9 months. Health Psychology, 24, 11-21.

Team in Training (2009). Retrieved February 2, 2009, from www.teamintraining.org

Vallerand, R. J. (1997). Toward a hierarchical model of intrinsic and extrinsic motivation. In M. P. Zanna (Ed.), Advances in experimental sport psychology, 29, 271-360. New York: Academic Press.

Vallerand, R., Deci, E., \& Ryan, R. (1987). Intrinsic motivation in sport. Exercise \& Sport Sciences Reviews, 15389-425. Retrieved from SPORTDiscus with Full Text database.

Vallerand, R. J., Pelletier, L. G., \& Koestner, R. (2008). Reflections on self-determination theory. Canadian Psychology, 49, 257-262.

Weinberg, R. S., \& Gould, D. (2007). Foundations of sport and exercise psychology. Champaign, IL: Human Kinetics.

Wininger, S. R. (2007). Self-determination theory and exercise behavior: An examination of the psychometric properties of the exercise motivation scale. Journal of Applied Sport Psychology, 19, 471-486. http://search.ebscohost.com.libaccess.sjlibrary.org, doi:10.1080/10413200701601466

Wright, P. M., Ding, S., \& Li, W. (2005). Relations of perceived physical self-efficacy and motivational responses toward physical activity by urban high school students. Perceptual and Motor Skills, 101, 651-656.

Youn, S., \& Kim, H. (2008). Antecedents of consumer attitudes toward cause-related marketing. Journal of Advertising Research, 48, 123-137. 
Chapter 3

\section{EXTENDED SUPPORT MATERIAL}

\section{Introduction}

In the late 1980s a new philanthropic paradigm emerged in the United States in the form of the cause-based training program (King, 2006). Such programs combined charitable fundraising with endurance-sport fitness training (King, 2006). Program participants committed to raise a predetermined amount of funds and, in return, were coached and trained to complete a specific endurance sport event such as a marathon (Havenar \& Lochbaum, 2007).

According to the Leukemia \& [sic] Lymphoma Society’s (LLS’s) Team in Training (TNT) program (Team in Training, 2009), the program concept originated with New York State resident Bruce Cleland, whose daughter was diagnosed with leukemia in 1988. Cleland and several friends decided to train for the New York City Marathon, leveraging their training commitment to ask family and friends to donate to the LLS. The members of Cleland's informal team collectively raised \$322,000 for the LLS and each of them completed the marathon (Team in Training, 2009).

The LLS subsequently formalized this model as TNT program, expanding it throughout the United States and then internationally. As of its 20th anniversary in 2008, TNT had registered over 360,000 participants, raised over $\$ 850,000,000$, and become the world's largest endurance sport training program of any kind (Team in Training, 2010).

This combination of fundraising and endurance training proved so successful that it was rapidly adopted by several other for-profit and non-profit organizations, 
particularly those with missions to fight specific diseases. A for-profit example was the for-profit Pallotta TeamWorks AIDSRides, held in various locations in the United States and now nonexistent (King, 2006). Three contemporary examples include two series of fundraising walks for breast cancer, the Avon Walk for Breast Cancer (Edwards, 2006) and the Susan G. Komen Breast Cancer 3-Day (King, 2006), also held in various states; and the still-thriving Team in Training program, which continues to be a worldwide presence (Team in Training, 2009).

Currently, these programs continue to gain both popularity and participants (King, 2006; Nettleton \& Hardey, 2006). One possible reason may be their claims, both implied and directly stated, that the cause provides a highly effective motivation to exercise.

For example, TNT encourages participants to frame their physical efforts, both to themselves and to potential sponsors, as the metaphorical equivalent of the suffering of leukemia/lymphoma patients (Team in Training, 2009). The TNT website also displays this unattributed quote: “Training’s tough. But chemo’s a whole lot tougher. It was the most worthwhile thing I ever did.” (Team in Training, 2009) The website of the Breast Cancer 3-Day displays the message: “Small sacrifice, big reward.” (Breast Cancer 3-Day, 2009) This suggests that a 60-mile walk on behalf of the cause is both achievable and worthwhile.

Interestingly, however, in each of the above programs, only the fundraising is actually mandatory for program participation. Attendance at program-provided coaching sessions, workouts, and even the target endurance event itself is encouraged but not required. 
Similarly, cause-based endurance-training programs often describe the participant experience as “successful,” "inspiring,” and "life-changing” (AIDS/LifeCycle, 2009; Team in Training, 2009). However, these terms are seldom defined, leaving them open to interpretation by potential recruits. For example, "success" may mean adhering to an exercise program, completing a long-distance endurance event, experiencing personal growth, and/or helping to fund cancer-curing research. The AIDS/LifeCycle provides vehicle support to participants who find themselves unable (or unwilling) to ride a bicycle for seven consecutive days (AIDS/LifeCycle, 2009). Similarly, the Komen Breast Cancer 3-Day assures participants that if they cannot continue, a support vehicle will bring them either to the closest rest stop or to the day's campsite (Breast Cancer 3Day, 2009). However, such participants are considered successful if their goals are defined as anything other than physically completing a specified distance. Inconsistent terminology is another contributing factor to the current lack of information on the relationship between cause-based training programs and the motivation to train.

Motivation in general has been researched extensively in sport and exercise psychology (Biddle, 1999; Dishman, 2001; Dishman \& Sallis, 1994; Roberts, 1993; Summers, Sargent, Levey, \& Murray, 1982; Taylor \& Fox, 2005). Numerous previous studies examined the motivations of marathoners (Havenar \& Lochbaum, 2007; Masters \& Ogles, 1995; Ogles \& Masters, 2000, 2003; Summers, Machin, \& Sargent, 1983; Summers et al., 1982). Some research also addressed other endurance sports such as triathlon and cycling (Hammermeister \& Burton, 2004). In addition, in the field of social psychology, several researchers examined the nature of altruism and volunteerism 
(Batson, 1991; Batson, Bolen, Cross, \& Neuringer-Benefiel, 1986). Many studies investigated the motivations for philanthropic behavior, including the relationship between altruism and motivations for actual volunteerism in charitable causes (Bennett \& Kottasz, 2000; Brammer, Millington, \& Pavelin, 2006; Eveland and Crutchfield, 2007). However, as stated previously, relatively few researchers have investigated the relationship between altruism, such as a commitment to a charitable cause, and the motivation to train for the cause (Havenar \& Lochbaum, 2007; King, 2006; Nettleton \& Hardey, 2006), or, as King (2006) framed it, to “do good by running well” (p. 29).

This study drew on research in both sport and exercise psychology and social psychology to examine participant motivations in cause-based endurance-training programs. A qualitative approach was used (Côte, Salmela, Baria, \& Russell, 1993; Cresswell, 2009; Dale, 1996; Martens, 1987). Because much of the previous research on endurance athletes focused on marathon runners (Havenar \& Lochbaum, 2007; LaCaille, Masters, \& Heath, 2004; Masters \& Ogles, 1995; Nettleton \& Hardey, 2006; Schomer, 1986; Schomer \& Connolly, 2002; Summers, Machin, \& Sargent, 1983), this study also involved marathon runners. Consistent with some of the literature in exercise psychology (Dale; Jackson, 1995), semi-structured interviews were used to gather thick and rich data to supplement and contextualize the quantitative results.

A more detailed understanding of the charitable trainee experience offers several potential benefits. At present, rates of obesity- and lifestyle-related diseases continue to rise in the developed world (Canada Fitness Survey, 1983; U.S. Department of Health and Human Services, 2009). Complications from sedentary lifestyles (coronary heart 
disease (CHD), diabetes, hypertension, obesity) affect an increasing percentage of the U.S. population, starting at ever-younger ages (www.cdc.gov, 2009). However, effective exercise interventions for the general population remain elusive (Chatzisarantis, Hagger, Biddle, Smith, \& Wang, 2003). About 50\% of all people who start an exercise program stop within a year (Dishman, 2001; Martin \& Dubbert, 1982). This includes individuals for whom exercise may literally mean life or death (Martin \& Dubbert, 1982), such as those who are either at risk for or in rehabilitation from CHD.

Therefore, if cause-based training programs are, as they imply, truly effective in helping participants adopt more active lifestyles, research into the contributing factors could lead to more effective exercise motivation interventions. The cause-based training model might be leveraged to increase physical activity levels in the general population in order to help meet the guidelines for a weight-control lifestyle (U.S. Center for Disease Control, www.cdc.gov, 2009). In addition, from the philanthropic perspective, such programs might raise more funds to eradicate or mitigate life-threatening diseases.

\section{Statement of Purpose}

Cause-based training programs frequently use recruitment messages implying that the cause provides a guaranteed motivation to exercise. However, little research has examined this assumption. Therefore, the purpose of this study was to qualitatively research runners in a cause-based marathon-training program, particularly the relationship between the cause and the runners' motivations to train consistently.

\section{Definition/Description of Terms}

This study used the following terms: 


\section{Cause-Based Training Program (also, Cause-Based Endurance Sport}

Training Program, Charitable Cause-Based Training Program): is defined as a fundraising and endurance-training program provided by a philanthropic organization, often one dedicated to curing a specific disease. This type of program provides participants with exercise guidelines, a training schedule designed to enable successful completion of a target endurance event, and/or other benefits such as event registration. In return, the participant commits to raise a predetermined amount of donations for the charitable cause.

2. Endurance Event: is defined as an extended distance athletic event, such as a half-marathon run (13.1 miles) or a bicycle ride of at least 50 miles.

3. Endurance Run: is defined as a run that is longer than the standard " $10 \mathrm{k}$ " (10-kilometer/6.2 mile) race distance, such as a half marathon (13.1 miles) or full marathon (26.2 miles).

4. Novice or "Rookie” Marathon Runner: is defined as a runner training for his or her first marathon. The term "rookie" is used for consistency with previous research (Masters \& Ogles, 1995). No pejorative meaning is implied or intended.

5. Recreational Athlete: is defined as a non-professional endurance athlete, that is, an athlete who participates and/or competes in endurance sports as a leisure activity rather than as a vocation (Ogles \& Masters, 2000). 


\section{Delimitations}

This study was delimited to the following participants:

1. Recreational runners who trained for and ran their first marathon with the Leukemia \& Lymphoma Society’s (LLS’s) Team in Training (TNT) program.

2. Male and female runners of at least 18 years of age.

3. Runners residing in the San Francisco Bay Area of California.

This study was delimited to the following instruments:

1. Background questionnaire including demographic information and previous endurance-training experience (Appendix E).

2. Interview guide (Appendix F).

\section{Limitations}

The limitations of this study included the following:

1. Participants may not have been willing or able to accurately articulate their training-related perceptions and experiences.

2. The motivational factors of marathon runners may differ from those of athletes training for other endurance sports (Schilling \& Hayashi, 2001).

\section{Summary}

This section described the background and purposes of this study. Despite the popularity of charitable cause-based endurance-training programs, the relationship between the cause and participant motivation has not been examined. Therefore, the purpose of this study was to qualitatively research the motivations of runners in a 
charitable cause-based marathon-training program, particularly the relationship between the cause and the participants' motivations to train consistently.

\section{Review of Literature}

This section examines one of the first precursors of contemporary cause-based training programs, the Marathon of Hope (Coupland, 2005; Scrivener, 2000). It then describes four representative contemporary programs in chronological order of their emergence: Team in Training, the AIDS/LifeCycle, the Avon Walk for Breast Cancer, and the Susan G. Komen Breast Cancer 3-Day. This section then considers theories of motivation in relation to exercise, as well as motivation in terms of altruism, philanthropy, and charitable volunteerism. The purpose of this study was to qualitatively research the motivations of runners in a cause-based marathon-training program, particularly the relationship between the cause and the participants' motivations to train consistently.

\section{The Marathon of Hope}

The Marathon of Hope was conceived and executed by Canadian athlete Terry Fox (Coupland, 2005; Scrivener, 2000). In 1977, at age 18, Fox lost his right leg to cancer. In 1979 he decided to run across Canada, a distance of 5300 miles. In 1980 the marathon was considered an elite, Olympian-level sport (Coupland, 2005; King, 2006; Ogles \& Masters, 2000) with no conceivable participation by amputees (Coupland, 2005). Moreover, while cross-Canada endurance events are now common, in 1980 they were unheard-of (Coupland, 2005). Thus Fox's primary goal was to be a role model and an inspiration to other cancer patients, survivors, and amputees. His secondary goal 
(Coupland, 2005; Scrivener, 2000) was to raise funds for the Canadian Cancer Society (CCS).

In 1980 Fox ran 3339 miles across Canada over the course of 143 days (Coupland, 2005). He averaged over 23 miles a day, just a few miles under a marathon. He also raised \$1.4 million for cancer research (Scrivener, 2000). He was then forced to stop because his cancer had returned and spread to his lungs (Scrivener, 2000). He died the following year.

Fox’s Marathon of Hope differed from today’s typical cause-based endurancesport training programs in several ways. For example, by contrast with most contemporary programs, Fox essentially was the program itself. That is, he was both cancer patient and participant; he embodied both cause and connection. His run was a literal extension of his ordeal with cancer, not a metaphorical one. He was also the only participant, although other runners joined him for some parts of the journey.

In addition, today's programs typically offer coaching and/or training as an incentive to join. By contrast, Fox created his own training schedule, venturing into uncharted territory since, at the time, no one had ever attempted such a run, let alone an amputee (Scrivener, 2000).

Finally, contemporary programs typically manage most of the logistics for their participants, such as event registration, travel, lodging, and equipment transportation. However, Fox had no parent agency to manage or support his effort. He created his event as he ran it, rather than participating in an existing event, and he managed all the logistics himself, with some support from family and friends. The CCS, which could have taken 
on the role of parent organization, provided only sporadic support, often seeming to be more of an actual hindrance than a help (Scrivener, 2000). It is possible that they simply did not recognize the potential publicity and fundraising opportunities in Fox's effort, since this was one of the first events of its kind.

However, in one important way, Fox’s program predicted the contemporary model. He undertook a true physical challenge, something that no one had ever attempted: running consecutive daily marathons in order to traverse Canada. He thus set a precedent that gained considerable momentum ten years later, as described below.

\section{Contemporary Cause-Based Endurance-Training Programs}

Today several non-profit organizations, particularly those committed to curing a specific disease, offer programs similar to that of Fox, but with several fundamental differences. For example, they actively streamline the participant experience by managing most of the logistics of fundraising and training. In addition, they either transport participants to existing endurance events, as TNT does, or organize their own events. For example, the American Diabetes Association offers the Tour de Cure, an annual series of endurance bicycling events across the U.S. (American Diabetes Association, 2009). Similarly, the Vineman Cancer Charities Fund holds an annual series of multisport events in Northern California (Vineman, 2009). New events continue to be added throughout the developed world each year. In fact, according to King (2006), it is now almost impossible to find an endurance sport event that is not also connected with a charitable cause.

The present review of literature includes four established programs that follow 
similar models for fundraising and training. These programs, in chronological order of their launch, are Team in Training, the AIDS/LifeCycle, the Avon Walk for Breast Cancer, and the Susan G. Komen Breast Cancer 3-Day. The following descriptions have been retrieved directly from these programs' promotional media, including postal mail, email, and websites. Additional information has been retrieved from peer-reviewed historical studies of these programs (see Edwards, 2006; King, 2006).

Team in Training. The Leukemia \& Lymphoma Society (LLS) claims to have originated cause-based endurance training with its Team in Training program, or TNT (Team in Training). TNT credits Bruce Cleland of Rye, NY with the original inspiration (Team in Training, 2009). In 1998 Bruce Cleland and several friends took on a challenge similar to Fox's: they trained for the New York City Marathon while soliciting donations to the LLS in honor of Cleland's daughter, a leukemia patient. According to Ogles and Masters (2000), "rank and file" runners only began to "shuffle along” (p. 131) after the 1970s, and in 1988 the marathon was still considered more of a superhuman undertaking than an activity for mere mortals (King, 2006). Thus Cleland and his friends may have actually helped originate the concept of “doing good by running well” (King, 2006, p. 29).

The LLS subsequently formalized Cleland's model as its Team in Training (TNT) program. Since then, TNT has expanded internationally and has become "the largest endurance sports training program in the world" of any kind, cause-based or otherwise (Team in Training, 2009). 
The AIDS Life/Cycle and the Avon Breast Cancer 3-Day Walk. These programs are discussed together because they were produced by the same organization and consequently had linked histories. In 1993, Pallotta Teamworks, a for-profit, selfstyled cause-related marketing corporation (Edwards, 2006; Olsen, Pracejus, \& Brown, 2003), launched the California AIDS Ride. This involved a bicycle ride of approximately 500 miles from San Francisco to Los Angeles (Edwards, 2006). Over the next few years Pallotta Teamworks expanded this ride to six locations in the U.S.

In 1998 the Avon Corporation partnered with Pallotta to premiere another California fundraising event, the Avon Breast Cancer 3-Day Walk (King, 2006). Like the AIDS ride, this event quickly expanded from one location into a series throughout the U.S. In the late 1990s, it was the source of most of the funds raised for breast cancer research and patient services (Edwards, 2006).

However, in the early 2000s, both the AIDS Ride and the Avon Walks faced growing accusations that most of the donations collected never reached the supposed beneficiaries (Brenner, 2000; King, 2006). The Breast Cancer Action (BCA), after tracking the actual donation destinations, reported that less than $65 \%$ of this money actually went to breast cancer organizations (Brenner, 2000). Moreover, an undisclosed percentage of this amount went directly to Avon itself (Brenner, 2000; King, 2006).

In 2002 the San Francisco AIDS Foundation and the Los Angeles Gay \& Lesbian Center collaborated to produce their own charitable bicycle event. The AIDS/LifeCycle (AIDS/LifeCycle, 2009), like the AIDS Ride, was a 500-mile ride from San Francisco to Los Angeles. The stated goal of the two organizations was to provide better oversight 
and management of the funds raised (AIDS/LifeCycle, 2009). Another goal may have been to re-legitimize donations to HIV/AIDS-related causes, which had historically been on more tenuous ground than other health-related charitable causes (Eveland \& Crutchfield, 2007). By 2008 the AIDS/Lifecycle had more than doubled its annual fundraising total, simultaneously reducing its fundraising costs by over $25 \%$ (AIDS/LifeCycle, 2009).

Also in 2002, Avon abruptly withdrew its title sponsorship of the Breast Cancer Walks mid-series (Edwards, 2006). Two months later, Avon launched the Avon Breast Cancer Crusade (Edwards, 2006; Avon Breast Cancer Crusade, 2009). The Crusade included Avon's new proprietary fundraising walking event, the Avon Walk for Breast Cancer (Avon Walk for Breast Cancer, 2009), which greatly resembled the Breast Cancer Walk, but without Pallotta as the producing agency. Also by 2008, the Avon Breast Cancer Crusade, including the walks, had raised over \$585 million (Avon Breast Cancer Crusade, 2009).

Thus, despite certain aspects of its history, the fundraising endurance-training model survived. This may have been because the beneficiary organizations collaborated with the supporting and/or participating public to monitor such programs. It may also have been because the basic program model was robust enough to withstand such setbacks.

\section{Key Components of Cause-Based Training Programs}

The four cause-based training programs described above share two key components: the charitable cause and the participant commitment. All four programs 
position the first component as a motive for success in the second, as the following sections describe.

The charitable cause. In the cause-based training model, the charitable cause can be almost anything, such as reducing world hunger or protecting wildlife. However, this study focuses on programs wherein the cause is a disease that is often terminal, although some treatments exist. This component also includes the nature and extent of the connections which the program attempts to forge between the cause and the program participants. For example, Team in Training (Team in Training, 2009) starts by introducing participants to actual patients and/or survivors of blood-related cancers. According to the TNT website (Team in Training, 2009), “a key element of the TNT experience is getting to know your honored teammate - a local blood cancer patient whose courage provides motivation and inspiration.” TNT encourages participant-patient contact and bonding throughout the program (King, 2006). This direct, personal connection is clearly intended to make the cause less abstract and more personal. In fact, some program participants themselves have, or have survived, the specific disease or condition (Edwards, 2006).

These programs also create other less immediate connections with the cause by featuring patients or survivors as speakers at program events and/or by profiling them online. Patients and/or survivors may also attend the endurance event either to participate themselves or to cheer on other participants.

The participant commitment. The participant commitment, the second key component of cause-based training programs, actually involves three distinct 
commitments: fundraising, preparation (training) for a pre-selected endurance event, and completion of the event. These commitments are described in detail below.

Commitment to fundraise. Cause-based endurance-training programs frequently promote the cause as a motivational factor for fundraising. For example, these programs emphasize that participants should not hesitate to ask for donations because they are fundraising for the cause, not for themselves (AIDS/LifeCycle, 2009).

In the four programs considered here, the charitable organization specifies a fundraising minimum per participant. In Team in Training these minimums vary according to the LLS's cost per participant per event, which includes factors such as event transportation and accommodation. In the other three programs, the minimum is fixed: \$3000 for the AIDS/LifeCycle, \$1800 for the Avon Breast Cancer Walk, and \$2300 for the Susan G. Komen Breast Cancer 3-Day. In all four programs, participants can only register by committing in advance to raise the minimum. As part of this commitment, participants sign an agreement stating that, should they fail to raise this amount by a specified pre-event deadline, they will donate the balance themselves.

Commitment to prepare (train) for a pre-selected endurance event. Historically, charitable volunteers have donated their free time and/or money to help with projects such as community soup kitchens and food drives (Bennett \& Kottasz, 2000). By doing so, these volunteers feel positive about themselves (Bennett \& Kottasz). However, in the new paradigm of cause-based training programs, physical activity has been reframed as charitable work. Volunteers now donate their time and energy to get fit, which provides several tangible rewards in addition to positive feelings. 
Cause-based training programs use a variety of messages to emphasize the motivating power of the cause. These messages can be particularly dramatic when the cause is a serious or terminal disease. As both Edwards (2006) and King (2006) observed, messages and meanings related to the cause and participant commitment interact in complex ways of which the typical participant is probably unaware. For example, Team in Training encourages participants to frame their physical efforts, both to themselves and to potential sponsors, as the metaphorical equivalent of the suffering of leukemia/lymphoma patients (Team in Training, 2009). This metaphorical association between illness and physical exertion can be extended to an association between the participant's willingness to suffer and the "morality" of athleticism and fitness (King; Murray, 2008; Zanker \& Gard, 2008). It is almost a modern form of mortification of the flesh. However, this form of "mortification" benefits rather than punishes the body, while also elevating the soul. Moreover, participants, unlike actual patients, have control over the extent and duration of their physical involvement.

The current panoply of cause-based endurance programs offers a range of training "plans" which vary in their levels of detail, specificity, and personalization. Team in Training (Team in Training, 2009) provides a detailed daily workout schedule for at least three months prior to the event, plus multiple opportunities for group workouts with “professional certified coaches” (Team in Training, 2009), a potentially questionable claim, since TNT is itself the certifying body for these coaches. The AIDS/LifeCycle (AIDS/LifeCycle, 2009) offers general training guidelines that become available via email and/or Internet when a participant registers for the program. The AIDS/LifeCycle 
also offers a "Participant Representative" to help personalize these guidelines (AIDS/LifeCycle, 2009) and provides a schedule of organized training rides. The Avon Walk offers "a training program to help you to begin walking short distances and increase your mileage over time, plus volunteer-led Training Walks to train with other Walkers” (Avon Walk for Breast Cancer, 2009). The Komen Breast Cancer 3-Day promises that upon registration, participants will receive all necessary training resources, including a walker handbook, a website-based training schedule, and other web-based training tools (Breast Cancer 3-Day, 2009).

Commitment to complete the endurance event. In the four cause-based training programs discussed here, participants train to complete a pre-selected endurance event such as a marathon, long-distance bicycle ride, or long-distance walk. All four programs invoke the cause as a motivating factor, as they do in relation to fundraising and training. In so doing, as stated previously, these programs expand traditional modes of volunteerism (Bennett and Kottasz, 2000) into a willingness to endure physical discomfort as a version of the patient's ordeal. The implicit message is that completing an endurance event is somehow analogous to living with cancer or AIDS. A further implicit message is that people, when aligned with a good cause, can accomplish athletic feats of which they did not believe themselves capable.

It should be noted that the programs under discussion deliberately emphasize “completing” the endurance event rather than "racing” or "winning” it. All four programs downplay the concept of competition. For example, the AIDS/LifeCycle website (AIDS/LifeCycle 2009) states that "it’s a life-changing ride - not a race.” 


\section{Theories of Motivation in Sport and Exercise Psychology}

As stated, cause-based endurance-training programs often claim that the cause automatically motivates participants to meet their training commitments. However, actual research on the specific relationship between cause and motivation is sparse (Havenar \& Lochbaum, 2007; King, 2006; Nettleton \& Hardey, 2006). This section examines three major theories of motivation in sport and exercise psychology: selfefficacy theory (Bandura, 1997), achievement goal theory (AGT) (Duda, 1989; Duda \& Hall, 2001), and self-determination theory (SDT) (Deci \& Ryan, 1985, 2008).

Self-efficacy theory. Self-efficacy is the belief in one's ability to accomplish a specified task or achieve a specified goal (Bandura, 1991). Self-efficacy theory defines motivation as “a general construct that encompasses a system of self-regulatory mechanisms” (Bandura, 1997, p. 228). Harter (1978) describes motivation in terms of a related concept, perceived competence.

Motivation can be inferred from three behavioral components: the selection, activation, and sustained direction of specific behaviors toward a goal Bandura (1991). Thus if a novice runner selects, joins, and then adheres to a cause-based marathontraining program, this behavior indicates a high level of motivation. According to selfefficacy theory, the runner's motivation stems from the belief that he is capable of such adherence.

Wright, Ding, and Li (2005) studied the relation between self-efficacy and motivation for physical activity in 46 urban teenagers. Their results indicated that teenagers were more motivated to exercise if they had higher perceptions of their 
physical ability, that is, of their physical self-efficacy. These results suggested that interventions helping adolescents increase physical self-efficacy might be effective in increasing their levels of physical activity.

However, self-efficacy theory does not explain all aspects of participant behavior in cause-based training programs. For example, according to Duda and Treasure (2006), self-efficacy considers previous performance to be a significant factor. Therefore, since cause-based training programs frequently recruit what Masters and Ogles termed “rookie” athletes (1995), other factors must account for the ways in which novice participants build confidence in their ability. In addition, marathon training involves physical exertion, discomfort, and inconvenience (Kretchmar, 2001). It is unclear what motivates participants to tolerate these factors when there are more comfortable ways to develop a similar degree of self-efficacy (Kretchmar, 2001). Finally, McAuley and Blissmer (2000) and Raglin (2001) have suggested that self-efficacy is a significant factor in exercise adoption but not in exercise adherence.

Achievement goal theory. Achievement goal theory (AGT) suggests that personal goals can influence the individual's thoughts, feelings, and behavior in achievement situations (Duda, 1989; Duda \& Hall, 2001; Maehr \& Nicholls, 1980; Mallett \& Hanrahan, 2004; Roberts, 1993). AGT suggests three subscales of goal orientation: task, ego, and social goal orientation. In task goal orientation, also referred to as mastery goal orientation (Nicholls, 1984) or learning goal orientation (Dweck, 1986), agents focus on making their best effort and improving their skills. In ego goal orientation, also referred to as performance goal orientation (Nicholls, 1984; Dweck, 
1986) or competitive goal orientation, agents strive to outperform others, defining their ability in comparison to others' performance (Biddle, 1999). Finally, in social goal orientation (Maehr \& Braskamp, 1986; Maehr \& Nicholls, 1980; Urdan \& Maehr, 1995), agents focus on the perceived social functions of athletic success or failure. These three orientations represent dimensions of motivation rather than a continuum. That is, most individuals operate in one or more dimensions depending on the situation. For example, agents with a social goal orientation may define athletic success and failure in taskoriented terms, ego-oriented terms, or a combination of both.

Schilling and Hayashi (2001) qualitatively examined 12 high school athletes and the goal orientation dimensions in which they operated. Six of the participants were basketball players and six were cross-country runners. The results indicated that all 12 athletes operated in all three dimensions, but to differing extents depending on their sport. For example, the basketball players emphasized the ego goal of winning, while the runners did not. Schilling and Hayashi noted that in team sports such as basketball, every team either wins or loses, whereas in individual endurance sports, races may have tens or even hundreds of competitors, which greatly lowers the odds of "winning” outright. Therefore, Schilling and Hayashi suggested that achievement goal orientations may differ according to the specific sport.

Kilpatrick, Bartholomew, and Riemer (2003) addressed a research gap by investigating achievement motivation in the exercise domain as opposed to the sport domain. They used Duda’s (1989) Task and Ego Orientation in Sport Questionnaire (TEOSQ) to develop the Goal Orientation in Exercise Scale (GOES). In their initial 
study, Kirkpatrick et al. administered the GOES to over 200 exercisers with diversity in age, gender, race, and exercise background. The results indicated that these exercisers used several of the same self-evaluation and achievement criteria as sport participants. In other words, exercisers and sport participants had similar achievement motivations. The results also suggested that the GOES was a valid measure of exercise achievement goal orientation.

Koo and Fishbach (2008) conducted four studies investigating the relationship of motivation to achieved vs. unachieved goals. Each study used a 2 x 2 between-subjects design to compare what participants had already accomplished toward their goal with what they still needed to accomplish. A total of 383 men and women participated in the four studies. The researchers identified two motivational relationships between level of commitment and amount of progress. Agents not fully committed to a goal were motivated by focusing on their accomplishments thus far. By contrast, agents fully committed to a goal were motivated by focusing on what they still needed to do to achieve it.

Achievement goal theory and its subscales of goal orientation are related to selfdetermination theory and its subscales of extrinsic and intrinsic motivation (Deci \& Ryan, 1985, 2000, 2008) as described below.

Self-detemination theory. Self-determination theory (SDT; Deci and Ryan, 1985, 2000, 2008) describes motivation as a continuum of self-regulation between amotivation, extrinsic motivation, and intrinsic motivation (Deci \& Ryan, 1985, 2000; Li, 1999; Ryan \& Deci, 2000). According to SDT, motivation exists on a continuum of self- 
regulation between amotivation, extrinsic motivation, and intrinsic motivation (Deci \& Ryan, 1992, 2002; Li, 1999; Ryan \& Deci, 2000). Extrinsically motivated individuals are less invested in the activity itself than in its accompanying external rewards, such as recognition or social status (Deci \& Ryan, 1985; Duda \& Treasure, 2006; Landry \& Solmon, 2004). Intrinsically motivated individuals pursue an activity because they enjoy it or are otherwise invested in it for its own sake. In this model, intrinsic motivation is the most self-regulated and most effective form of motivation (Deci \& Ryan, 1985, 2002; Vallerand, 1997). However, the continuum of motivation includes multiple stages of self-regulation involving various combinations of extrinsic and intrinsic motivational factors (Deci \& Ryan, 1985; Landry \& Solmon, 2004; Li, 1999). SDT thus recognizes individual differences by acknowledging that while any factor, including a charitable cause, is potentially motivating, it is impossible to predict whether it is actually motivating without a deeper understanding of the extrinsic and intrinsic motivating factors specific to each individual.

To help measure these complex individual factors $\mathrm{Li}$ (1999) created an instrument to assess motivation for physical activity, the Exercise Motivation Scale (EMS). Li (1999) tested the EMS in three studies involving male and female college undergraduates. The first study used a phased approach to create the EMS items. The second and third studies administered the EMS to a total of 942 participants. Statistical analyses indicated that the EMS was a reliable and valid instrument for interpreting data on exercise motivation (Li, 1999; Wininger, 2007). In two subsequent studies, Wininger (2007) administered the EMS to 200 male and female college undergraduates. The 
results supported the reliability and validity of the psychometric properties of the EMS. However, Wininger (2007) also noted that test-retest reliability had not yet been established and should be examined in the future.

\section{Motivation in Exercise and Running}

Several researchers have examined the motivational and amotivational factors related to consistent physical activity (Dishman, 2001; Dishman \& Sallis, 1994; Gill, 1987; Li, 1999; Wininger, 2007; Wright, Ding, \& Li, 2005). Dishman (2001) identified several issues hindering research in this area, including a tendency to focus more on exercise adoption than on adherence. He also stated that although motivation is often described in terms of “direction, intensity, and persistence” (p. 281), exercise motivation research typically addresses only one of these aspects, direction.

Li (1999) developed the Exercise Motivation Scale (EMS) both to assess all aspects of motivation more effectively, and to do so in the exercise context rather than the sport context (Vallerand, Deci, \& Ryan, 1987). His initial results with the EMS, which involved male and female college undergraduates, suggested that consistent exercisers were more intrinsically motivated than sporadic exercisers (Li, 1999). In another study using a more multidimensional approach to motivation, Wright et al. (2005) suggested that adolescents were more motivated to exercise if they had a strong sense of physical self-efficacy (Bandura, 1997). That is, interventions to help adolescents increase selfefficacy might also help motivate them to be more physically active (Wright et al., 2005) even if such interventions did not directly address the direction aspect of motivation. Gill (1987) encouraged an even more multidimensional approach to exercise motivation. He 
stated that applied sport psychology could benefit from incorporating more social psychological perspectives, because exercise behavior occurred in social contexts (Gill, 1987). This approach was supported by the present study, in which interpersonal interaction emerged as a strong contributor to intrinsic motivation, as discussed below.

Ever since Morgan and Pollock (1997) published their groundbreaking study on cognitive strategies in marathoners, substantial research has focused on runners in general (Butryn \& Furst, 2003; Goode \& Roth, 2003; Mallett \& Hanrahan, 2004; Schilling \& Hayashi, 2001) and on marathoners in particular (LaCaille, Masters, \& Heath, 2004; Masters \& Ogles, 1995; Nettleton \& Hardey, 2006; Schomer, 1990; Schomer \& Connolly, 2002; Summers, Sargent, Levey, \& Murray, 1982; Summers, Machin, \& Sargent, 1983). Numerous studies have examined marathoners' motivations from a variety of perspectives. This section provides a partial review of this literature.

Several studies have focused on the motivations of recreational runners training for their first marathon. Summers, Sargent, Levey, and Murray (1982) surveyed 363 such runners, all of whom were between 30 and 50 years of age. Summers et al. (1982) reported that $40 \%$ of these runners reported goal achievement as their main motivation, a category which included both personal challenge and the sense of achievement. It is unclear how this $40 \%$ was derived, since these same two factors appeared to represent $29 \%$ of the total responses, and the derivation of the other $11 \%$ was not explained. However, despite these minor inconsistencies, the results still suggested that personal challenge and the sense of achievement were the two main motivating factors for runners attempting their first marathon. 
Scholz, Nagy, Shüz, and Ziegelman (2008) also examined motivation in runners attempting their first marathon. They studied 30 participants between 24 and 56 years of age, similar to those in the study by Summers, Sargent, Levey, and Murray (1982). After one year of training, participants attended a marathon in Mainz, Germany. Thirteen of the participants ran the full marathon, ten ran shorter distances that were also officially offered during the event, and seven either did not finish or did not start. Data analysis suggested that increasing levels of self-efficacy and positive outcome expectancies were positively correlated with a successful marathon outcome. However, these results required clarification in several important areas. For example, the results were presented in terms of runners versus non-runners, without distinguishing between runners who completed the full distance versus those who ran one of the shorter options. Moreover, it was not clear whether the shorter distance runners chose this option in advance or during the marathon itself. Finally, of the seven participants whom the authors identified as nonrunners, the study stated that three withdrew from the program due to injuries, but did not specify whether the other four did not start the marathon, or started but did not finish. Such distinctions are important for a thorough understanding of motivational and volitional factors in marathoners.

Havenar and Lochbaum (2007) used the SDT framework to examine the motivations of runners training for their first marathon. This study was unique in two ways. First, according to the authors, it was the first to measure participant motivations before the actual event rather than retrospectively. Scholz, Nagy, Shüz, and Ziegelman used a similar approach in their 2008 study by collecting participant data for a year 
before the marathon event, although apparently without referring to Havenar and Lochbaum's (2007) study, which is not listed in their references.

The second, possibly unintentional, reason for the uniqueness of Havenar and Lochbaum's (2007) study was that all participants were recruited from a cause-based training program. While this aspect was peripheral to the original study, it seemed to lend unexpected significance to the results. Of the original 106 participants, only 31 completed the training and the marathon, while the remaining 75 dropped out. Data analysis suggested that the dropouts were more focused on social and weight-related motivational concerns than the finishers. Havenar and Lochbaum (2007) suggested that these participants met their social goals through the fundraising alone and thus had no need to complete the physical components of the program. Therefore, according to SDT (Ryan \& Deci, 2000), the 71\% dropout rate could have indicated a mismatch between participant motivations and the actual training program. These questions bear directly on the present study of marathoners' motivations in cause-based training programs, and as Havenar and Lochbaum (2007) suggested, merit further research.

The three studies described above involved runners preparing for their first marathon. Numerous other studies have involved marathoners with a greater range of experience. Summers, Machin, and Sargent (1983) surveyed 459 recreational marathoners. The sample included both first-timers and experienced marathoners. The age range was 14 to 61 , with a median age of 31.7. Consistent with the previous study by Summers, Sargent, Levey, and Murray (1982), goal achievement, including personal challenge and a sense of accomplishment, emerged as the main intrinsic motivation for 
running marathons. However, since SDT (Deci \& Ryan, 1985) describes motivation as a continuum from extrinsic to intrinsic factors, Summers et al. (1982) speculated that the marathon's increasing popularity was because it allowed runners to meet a range of needs along the entire motivation continuum. That is, individuals could meet both extrinsic goals such as social recognition and intrinsic goals such as self-fulfillment. Interestingly, the results also indicated that as participants aged, they became more motivated by factors related to their physical health (Summers et al., 1982). The SDT framework suggested that older marathoners became more motivated by intrinsic mastery goals and specifically of retaining mastery over their own bodies throughout the aging process.

In 1993, Masters, Ogles, and Jolton (1993) introduced an instrument for measuring marathoners' motivations, the Motivations of Marathoners Scales (MOMS). Also in 1993, Ogles, Lynn, Hoefel, Marsden, and Masters (1993) reported that early results for the MOMS indicated that it was a reliable and valid instrument. Preliminary results for the MOMS were consistent with those of Summers, Machin, and Sargent (1983). For example, the MOMS suggested that runners in their 20s were primarily motivated by personal goal achievement, whereas runners in their 50s and over were more motivated by factors involving general health. In terms of experience level, the MOMS indicated that first-time marathoners were more motivated by personal goal achievement than were more experienced marathoners (Masters et al., 1993). Ogles and Masters (2003) used the MOMS in a cluster analysis of the motivations of 1519 marathoners. Their results suggested that marathoners fell into five distinct categories: Running Enthusiast, Lifestyle Managers, Personal Goal Achievers, Personal 
Accomplishers, and Competitive Achievers (Ogles \& Masters, 2003).

However, Havenar and Lochbaum (2007) identified potential limitations to the MOMS. They noted that prior to their own 2007 study, all research with the MOMS involved runners who had actually completed a marathon. That is, none of the runners surveyed had either dropped out of their training program, or had started to run a marathon without completing the distance. The authors (2007) therefore suggested that the MOMS was more accurate as a retrospective measure of motivation than as a prospective measure.

Havenar and Lochbaum (2007) also noted that the MOMS did not assess motivating factors related to involvement with a charitable cause. Of course such an assessment would not have been necessary when the instrument was first developed. However, now that a growing percentage of marathoners are running in charitable endurance-training programs, a revision might be appropriate in order to more accurately reflect the current marathoner population.

Finally, it should be noted that the MOMS, by excluding non-finishers, may also exclude a substantial portion of marathon runners. For example, non-finishers are often forced to abandon the race due to injury or other reasons, rather than by choice. Thus runners who are otherwise motivated to complete the marathon sometimes withdraw due to conditions over which they have no control. The MOMS might better represent marathoner motivations by including such runners.

\section{Altruism, Charitable Volunteerism, and Cause-Related Physical Activity}

This section reviews the literature on motivation in relation to altruistic behavior 
and charitable volunteerism (Batson, 1991; Batson, Bolen, Cross, \& Neuringer-Benefiel, 1986; Bennett \& Kottasz, 2000; Eveland \& Crutchfield, 2007; Youn and Kim, 2008). This section also reviews the literature on the relationship between altruism and physical activity (Nettleton \& Hardey, 2006; Havenar \& Lochbaum, 2007) although, as stated previously, relatively few such studies exist.

Motivation for various modes of altruistic behavior, including charitable giving and volunteerism, has been examined from a variety of perspectives. Social psychological research (Batson, 1991; Batson, Bolen, Cross, \& Neuringer-Benefiel, 1986) suggests that people tend to help others for whom they feel empathy, because they experience positive feelings as an intrinsic reward. When empathy is not present, altruistic behavior is more likely to be extrinsically motivated, such as by the prospect of a material or social reward (Batson, 1991; Batson et al., 1986). Similarly, Bennett and Kottasz (2000), in studying effective recruitment messages for charity volunteers, indicated that even altruistic individuals were drawn to advertisements that included potential enhancements to the ego and/or self-image. That is, even for genuine altruists, the potential external benefits of volunteerism are more attractive than volunteering for its own sake (Eveland \& Crutchfield, 2007). Youn and Kim (2008) also suggested that when consumers responded positively to cause-related marketing, it was more often associated with the promise of extrinsic than intrinsic rewards. In other words, individuals at all points on the altruism continuum are attracted to potential extrinsic rewards. By extension, in cause-based training programs, it is possible that these extrinsic rewards are more significant in exercise adoption than in adherence (McAuley 
\& Blissmer, 2000; Raglin, 2001).

Youn and Kim (2008) further suggested that in cause-related marketing, positive consumer responses were associated with an external locus of control. Thus messages promising an external regulating body might motivate individuals to join cause-based training programs. For example, as stated above, the FAQ page of the Avon Walk for Breast Cancer website (2009) offers a “comprehensive support system,” including a training program and opportunities to train with other walkers. Participants may interpret such general statements as promising high levels of individual support and supervision.

However, cause-based endurance-training programs differ substantially from other forms of charitable volunteerism because they typically involve commitments of long duration. None of the above-cited studies were designed to investigate whether initial positive responses based on extrinsic rewards were sustainable over a period of weeks or months. Havenar and Lochbaum's (2007) research, which did address this question, suggested that extrinsic rewards motivated people to join a cause-based training program but not to continue. They studied 106 runners attempting their first marathon in a cause-based training program. Of these participants, 75 dropped out and only 31 completed both the training and the marathon. This suggests that those 31 individuals were motivated by something other than the promise of extrinsic rewards and an extrinsic source of regulation.

The present study addressed the motivation not only to join a cause-based endurance-training program, but to adhere to it. The distinction between these two types of motivation is extremely important (Dishman, 2001; Kretchmar, 2001. Future studies 
can benefit from previous research (Dishman, 2001; Havenar \& Lochbaum, 2007; Weiner, 1986, 1995) by explicitly examining the differences between the motivation to start a physical activity program and the motivation to adhere to it.

\section{Qualitative Research}

Since Martens (1987) first challenged the objectivity of the scientific approach to sport psychology, qualitative research has been increasingly recognized as a valid research methodology (Creswell, 2009). Martens (1987) stated that orthodox science oversimplified the complexity of human behavior. Dale (1996) extended this concept by positioning the athlete as the primary expert on the athletic experience. Subsequent researchers (Creswell; Andrews, Mason, \& Silk, 2005; Schilling and Hayashi, 2001) have observed that thick and rich qualitative data can contribute to a deeper understanding of complex, multidimensional topics such as motivation. Côte, Salmela, Baria and Russell (1993) and Glesne (2006) proposed guidelines for organizing such qualitative data into higher order themes and dimensions. Consistent with this approach, the researcher used semi-structured interviews to encourage participants to describe their training-related motivations, perceptions, and experiences in a cause-based marathon program.

\section{Summary}

This review of literature examined the development and contemporary structure

of cause-based endurance-sport fitness training programs. It also examined the literature on motivation, both in general and in relation to exercise and altruistic behavior. While some studies acknowledge the potential relationship between charitable causes and endurance-training motivation (Havenar \& Lochbaum, 2007; King, 2006; Nettleton \& 
Hardey, 2006), more research is needed in this area. Therefore, the purpose of this study was to qualitatively research the motivations of runners in a cause-based marathontraining program, particularly the relationship between the cause and the participants' motivations to train consistently.

\section{Methods}

The purpose of this study was to qualitatively research the motivations of runners in a charitable cause-based marathon-training program. More specifically, the purpose was to examine the relationship between the cause and the participants' motivations to train consistently. This section describes the methods used in this study, including the recruitment and selection of participants, the methods and instruments used to collect and analyze data, and the establishment of trustworthiness.

\section{Participants}

This study focused on marathon runners for consistency with previous research (Havenar \& Lochbaum, 2007; Masters \& Ogles, 1995; Ogles \& Masters, 2003, Schomer, 1990; Summers, Sargent, Levey, \& Murray, 1982). The investigator first obtained approval from the San José State University Human Subjects-Institutional Review Board (see Appendix A). The investigator then recruited 13 participants from the Leukemia \& Lymphoma Society's (LLS's) Team in Training (TNT) marathon running training program (see Appendices B and C for The full text of the initial recruitment communications with TNT staff and runners). The number of participants was consistent with previous research on marathon runners (Schomer, 1990) and with previous qualitative research on athletes (Chase, 2008; Jackson, 1995). The final number of 
participants was determined when data saturation was reached (Seidman, 1998).

Both male and female participants were recruited. This was consistent with previous studies of exercise behavior in general (Li, 1999; Scott, Scott, Bedic, \& Dowd, 1999; Wininger, 2007), runners (Goode \& Roth, 1993; LaCaille, Masters, \& Heath, 2004), and marathoners (Ogles \& Masters, 2003; Schomer \& Connolly, 2002; Summers, Sargent, Levey, \& Murray, 1982). Previous research (Havenar \& Lochbaum, 2007) has raised questions regarding potential differences in the experience of novice or "rookie" marathoners (Masters \& Ogles, 1995) training for their first marathon, as opposed to runners who have completed at least one marathon. Therefore, to limit factors that may have influenced participant experience, participants were limited to "rookie" marathoners who had completed their first marathon run. All participants were California Bay Area residents and all were at least 18 years of age.

\section{Instrumentation and Equipment}

Background questionnaire. An optional background questionnaire (see Appendix E) was used to record each participant’s demographic information, previous exercise experience, and prior endurance sport training experience. Most of these data were not used in this study, except in a few cases where they directly affected the participant's experience. However, they may be used in a future quantitative or mixedmethods study.

Interview guide. A semi-structured interview guide (Appendix F) was used in this study. This interview guide included both main questions and follow-up probes about the participant's training-related motivations, perceptions, and experiences in the 
TNT program. The interview guide was designed by the investigator based on previous research (Butryn \& Furst, 2003; Dale, 1996; Jackson, 1995). An experienced qualitative researcher reviewed the interview guide in order to help ensure trustworthiness. The purpose of these interviews was to examine participants' motivations during their fundraising, training, and/or marathon participation.

Digital voice recorders. A Livescribe ${ }^{\mathrm{TM}} \mathrm{Pulse}^{\mathrm{TM}}$ Smartpen was used as a combination digital voice recorder and note-taking device. A 5th-generation Apple ${ }^{\circledR}$ iPod nano was also used as a backup recording device.

Interview transcription equipment. All interviews were transcribed verbatim by the investigator using Livescribe ${ }^{\mathrm{TM}}$ Desktop software in combination with Microsoft巴 Word software. Interviews were transcribed using an HP® Pavilion laptop computer and an $H P \circledast$ Mini notebook computer.

\section{Procedures}

Recruitment of participants. Before recruitment, the investigator obtained approval from the San José State University Human Subjects Institutional Review Board (IRB). The IRB approval is included in this study as Appendix A.

After receiving IRB approval, the investigator contacted a San Francisco Bay Area office of the Leukemia \& Lymphoma Society via email. The message described the proposed study in detail and requested permission to contact the two marathon run team managers directly. When permission was granted, the investigator emailed a description of the study to the marathon program managers (Appendix B), along with a brief selfintroduction and a message to prospective participants (Appendix C). The investigator 
also hand-delivered hard copies of this message (Appendix C) to the managers. The managers agreed both to forward the email message to their teams and to personally distribute the hard copies.

All prospective participants received two documents: the Agreement to Participate in Research (Appendix D) and the Research Participant Contact Information and Background Questionnaire (Appendix E). The Agreement (Appendix D) informed prospective participants that this study would use one individual interview to examine their perceptions and experiences of their first marathon. Participants were also informed that their average total time commitment would be 60 to 90 minutes, that all personal information would be kept strictly confidential, and that the study would refer to them only by code names.

Data collection. The investigator interviewed each participant individually and recorded the interviews with the participant's knowledge and consent. Interview times and locations were mutually agreed upon between each participant and the investigator. Every effort was made to maximize participant convenience.

The average time per interview was one hour. The investigator designed a semistructured interview guide based on previous qualitative research (Carter \& Bloom, 2009; Mallett \& Hanrahan, 2004). The interview guide included questions and follow-up probes about training-related motivations, perceptions, and experiences in the program. Thick and rich description was used to capture participant perceptions and experiences in as much detail as possible and to contextualize the results (Atkinson, 2000; Dale, 1996, 2000; Jackson, 1995, 1996; Sparkes, 2002). 
Data analysis. All interviews were transcribed verbatim by the investigator. Each transcript was checked for accuracy and reread to establish familiarity with the material. The transcribed interviews were inductively analyzed and coded for themes according to the procedures recommended by Côte, Salmela, Baria, and Russell (1993), Gratton and Jones (2004), and Jackson (1995). The data were first sorted into raw data themes, then into higher order themes, and finally into dimensions that were used to further analyze the participants' training-related motivations, perceptions, and experiences.

Trustworthiness. The investigator followed several established qualitative research procedures (Andrews, Mason, \& Silk, 2005; Dale, 1996 \& 2000; Glesne, 2006; Sparkes, 1998, 2002) to establish trustworthiness. These procedures are described in detail below.

During each phase of the present study, the investigator received feedback from a research professional with extensive experience in qualitative methodology. Before the start of data collection, this professional evaluated the original study proposal, methodology, and interview guide (Culver, Gilbert, \& Trudel, 2003). This professional also conducted a bracketing interview with the investigator (Dale, 1996 \& 2000). This interview allowed the investigator to experience her own interview process, to evaluate and improve the interview guide, and to identify any personal biases that might affect her interpretation of the data (Dale). The investigator transcribed this interview verbatim and discussed the results with the research professional to gain further awareness.

During data collection, the researcher prompted participants to provide thick and 
rich description in order to capture their perceptions and experiences in the greatest possible detail (Sparkes, 2002). This approach was consistent with the guidelines for participant-focused qualitative research as outlined by Dale (1996).

The investigator also kept a reflexive journal throughout the study. This journal served as both a "methodological log" (Dale, 1996, p. 24) and a record of the investigator's thoughts and feelings during data collection and analysis. Thus this journal helped the investigator maintain awareness of her attitudes and biases throughout the research process (Maxwell, 2005).

Member checking was used to allow participants to verify the accuracy both of the interview data gathered and of the investigator's interpretation of the data. Six of the participants responded to the investigator, all of whom confirmed that the transcripts represented them accurately. This member checking, or "respondent validation" (Maxwell, 2005), also helped the investigator maintain awareness of any personal biases that might have affected the recording and analysis of participant data.

After completing the qualitative data collection, the investigator performed an inductive thematic analysis. As recommended by Sparkes (1998), before the investigator completed this study, the above-mentioned research professional peer-reviewed all findings. This professional evaluated the study in terms of the original proposal, the methodology, the transcribed interviews, and the interpretation of the results (Sparkes). 


\section{Summary}

This section described the methodology used in this study. It described the selection and recruitment of participants, the instruments, equipment, and procedures to be used to collect data, and the data analysis methods. The purpose of this study was to research the motivations of runners in a charitable cause-based marathon-training

program, particularly the relationship between the cause and the participants' motivations to train consistently. 


\section{References}

AIDS/LifeCycle 7-Day 545 Mile Cycling Event to Support HIV/AIDS (2009). AIDS/LifeCycle measures of success. Retrieved February 5, 2009 from www.aidslifecycle.org

American Diabetes Association: Tour de Cure (2009). Tour de Cure. Retrieved October 14, 2009 from http://tour.diabetes.org/site/PageServer?pagename=TC_homepage

Andrews, D. L., Mason, D. S., \& Silk, M. L. (2005). Qualitative Methods in Sports Studies. New York: Berg.

Atkinson, M. (2000). Brother, can you spare a seat?: Developing recipes of knowledge in the ticket scalping subculture. Sociology of Sport Journal, 17, 151-170.

Avon Breast Cancer Crusade (2009). Retrieved February 13, 2009 from http://walk.avonfoundation.org

Avon Walk for Breast Cancer (2009). Avon walk FAQ. Retrieved February 13, 2009 from http://walk.avonfoundation.org/site/PageServer?pagename=walk_faq

Bandura, A. (1991). Social-cognitive theory of moral thought and action. In W. M. Kurtines and J. L. Gewirtz, (Eds.), Handbook of moral behavior and development: Vol I: Theory (pp. 45-103). Hillsdale, NJ: Erlbaum.

Bandura, A. (1997). Self-Efficacy: The Exercise of Control. W. H. Freeman and Company: New York.

Barrell, G., Chamberlain, A., Evans, J., Holt, T., Mackean, J. (1989). Ideology and commitment in family life: A case study of runners. Leisure Studies, 8, 249-262.

Batson, C. (2006). SIT or STAND?. Psychological Inquiry, 17, 30-38. doi:10.1207/s15327965pli1701_02.

Batson, C. D. (1991). The Altruism Question: Toward a Social-Psychological Answer. Hillsdale, NJ: Erlbaum.

Batson, C. D., Bolen, M. A., Cross, J. A., \& Neuringer-Benefiel, H. E. (1986). Where is the altruism in the altruistic personality? Journal of Personality and Social Psychology, 50, 212-220.

Bennett, R., \& Kottasz, R. (2000). Advertisement style and the recruitment of charity volunteers. Journal of Nonprofit and Public Sector Marketing, 8, 45-63. 
Biddle, S. J. H. (1999). Motivation and perceptions of control: Tracing its development and plotting its future in exercise and sport psychology. Journal of Sport and Exercise Psychology, 21, 1-23.

Brammer, S., Millington, A., \& Pavelin, S. (2006). Is philanthropy strategic?: An analysis of the management of charitable giving in large UK companies. Business Ethics: A European Review, 15, 234-245.

Breast Cancer 3-Day (2009). Welcome to the Breast Cancer 3-Day: Training. Retrieved March 10, 2009 from http://www.the3day.org/site/PageServer?pagename=training_landing

Brenner, B. A. (2000). Think twice before walking for a cause. SF Gate. Retrieved February 2, 2000 from http://www.sfgate.com/cgibin/article.cgi?file=/chronicle/archive/2000/02/01/ED84199.DTL.

Butryn, T. M., \& Furst, D. M. (2003). The effects of park and urban settings on the moods and cognitive strategies of female runners. Journal of Sport Behavior, 26, 335-355.

Canada Fitness Survey (1983). Fitness and Lifestyle in Canada. Ottawa: Directorate of Fitness and Amateur Sport.

Carter, A. D., \& Bloom, G. A. (2009). Coaching knowledge and success: Going beyond athletic experiences. Journal of Sport Behavior, 32, 419-437.

Chase, L. F. (2008). Running big: Clydesdale runners and technologies of the body. Sociology of Sport Journal, 25, 130-147.

Chatzisarantis, N., Hagger, M., Biddle, S., Smith, B., \& Wang, J. (2003). A meta-analysis of perceived locus of causality in exercise, sport, and physical education contexts. Journal of Sport \& Exercise Psychology, 25, 284-306. http://search.ebscohost.com.libaccess.sjlibrary.org

Côte, J., Salmela, J. H., Baria, A., \& Russell, S. J. (1993). Organizing and interpreting unstructured qualitative data. The Sport Psychologist, 7, 127-137.

Coupland, D. (2005). Terry: Terry Fox and His Marathon of Hope. Vancouver: Douglas \& McIntyre.

Creswell, J. W. (2009). Research Design: Qualitative, Quantitative, and Mixed Methods Approaches. Thousand Oaks, CA: SAGE Publications, Inc.

Culver, D. M., Gilbert, W. D., \& Trudel, P. (2003. A decade of qualitative research in sport psychology journals: 1990-1999. The Sport Psychologist, 17, 1-15. 
Curtis, J., \& McTeer, W. (1981a). Social influences in recruitment to marathoning. Review of Sports \& Leisure, 6, 58-82.

Curtis, S., \& McTeer, W. (1981b). Toward a sociology of marathoning. Journal of Sport Behavior, 4, 67-81.

Dale, G. A. (1996). Existential phenomenology: Emphasizing the experience of the athlete in sport psychology research. The Sport Psychologist, 10, 307-321.

Dale, G. A. (2000). Distractions and coping strategies of elite decathletes during their most memorable performances. The Sport Psychologist, 14, 17-41.

Deci, E. L., \& Ryan, R. M. (1985). Intrinsic Motivation and Self-Determination in Human Behavior. New York: Plenum Press.

Deci, E. L., \& Ryan, R. M. (2000). The "what” and "why” of goal pursuits: Human needs and the self-determination of behavior. Psychological Inquiry, 11, 227-268.

Deci, E. L., \& Ryan, R. M. (2008). Self-determination theory: A macrotheory of human motivation, development, and health. Canadian Psychology, 49, 182-185.

Dishman, R. (2001). The problem of exercise adherence: Fighting sloth in nations with market economies. Quest, 53, 27-294.

Dishman, R. K., \& Sallis, J. F. (1994). Determinants and interventions for physical activity and exercise. In C. Bouchard, R. J. Shepard, \& T. Stephens (Eds.), Physical activity, fitness, and health (pp. 214-238), Champaign, IL: Human Kinetics.

Duda, J. L. (1989). Goal perspectives, participation, and persistence in sport. International Journal of Sport Psychology, 20, 42-56.

Duda, J. L., \& Hall, H. (2001). Achievement goal theory in sport: Recent extensions and future directions. In R. Singer, H. Hausenblas, \& C. Janelle (Eds.), Handbook of sport psychology (2nd ed., pp. 417-443). New York: Wiley.

Dweck, C. S. (1986). Motivational processes affecting learning. American Psychologist, 41, 1040-1048.

Edwards, H. H. (2006). A rhetorical typology for studying the audience role in public relations communication: The Avon 3-Day disruption as exemplar. Journal of Communication, 56, 836-860. 
Eveland, V. B., \& Crutchfield, T. N. (2007). Understanding why people do not give: Strategic funding concerns for AIDS-related nonprofits. International Journal of Nonprofit and Voluntary Sector Marketing, 12, 1-12.

Glesne, C. (2006). Becoming Qualitative Researchers: An Introduction (3rd Ed.). Boston: Allyn \& Bacon.

Goode, K. T., \& Roth, D. L. (1993). Factor analysis of cognitions during running: Association with mood change. Journal of Sport \& Exercise Psychology, 15, 375389.

Gratton, C., \& Jones, I. (2004). Research Methods for Sports Studies. New York: Routledge.

Hammermeister, J., \& Burton, D. (2004). Gender differences in coping with endurance sport stress: Are men from Mars and women from Venus? Journal of Sport Behavior, 27, 148-164.

Harter, S. (1978). Effective motivation reconsidered: Toward a developmental model. Human Development, 21, 36-64.

Havenar, J., \& Lochbaum, M. (2007). Differences in participation motives of first-time marathon finishers and pre-race dropouts. Journal of Sport Behavior, 30, 270-279.

Jackson, S. A. (1995). Factors influencing the occurrence of flow state in elite athletes. Journal of Applied Sport Psychology, 7, 138-166.

Jackson, S. A. (1996). Toward a conceptual understanding of the flow experience in elite athletes. Research Quarterly for Exercise and Sport, 67, 76-90.

Kilpatrick, M., Bartholomew, J., \& Riemer, H. (2003). The measurement of goal orientations in exercise. Journal of Sport Behavior, 26, 121-136.

King, S. (2006). Pink Ribbons, Inc. Minneapolis: University of Minnesota Press.

Koo, M., \& Fishbach, A. (2008). Dynamics of self-regulation: How (un)accomplished goal actions affect motivation. Journal of Personality and Social Psychology, 94, 183-195.

Kretchmar, R. S. (2001). Duty, habit, and meaning: Different faces of adherence. Quest, 53, 318-325.

LaCaille, R. A., Masters, K. S., \& Heath, E. M. (2004). Effects of cognitive strategy and exercise setting on running performance, perceived exertion, affect, and satisfaction. Psychology of Sport \& Exercise, 5, 461-476. 
Landry, J. B., \& Solmon, M. A. (2004). African American women’s self determination across the stages of change for exercise. Journal of Sport \& Exercise Psychology, 26, 457-469.

Li, F. (1999). The exercise motivation scale: Its multifaceted structure and construct validity. Journal of Applied and Sport Psychology, 11, 97-115.

http://search.ebscohost.com.libaccess.sjlibrary.org, doi: 10.1080/10413209908402953

Maehr, M. L., \& Braskamp, L. A. (1986). The motivation factor: A theory of personal development. Lexington, MA: D. C. Heath.

Maehr, M. L., \& Nicholls, J. (1980). Culture and achievement motivation: A second look. In N. Warren (Ed.), Studies in cross-cultural psychology (Vol. 2, pp. 53-75). New York: Academic Press.

Mallett, C. J., \& Hanrahan, S. J. (2004). Elite athletes: Why does the 'fire' burn so brightly? Psychology of Sport and Exercise, 5, 183-200.

Martens, R. (1987). Science, knowledge, and sport psychology. The Sport Psychologist, 1, 29-55.

Martin, J., \& Dubbert, P. (1982). Exercise applications and promotion in behavioral medicine: Current status and future directions. Journal of Consulting and Clinical Psychology, 50, 1004-1017. http://search.ebscohost.com.libaccess.sjlibrary.org, doi:10.1037/0022-006X.50.6.1004

Masters, K., \& Ogles, B. (1995). An investigation of the different motivations of marathon runners with varying degrees of experience. Journal of Sport Behavior, 18, 69-79. Retrieved June 30, 2009, from PsycINFO database.

Masters, K. S., \& Ogles, B. M. (1998). The relations of cognitive strategies with injury, motivation, and performance among marathon runners: Results from two studies. Journal of Applied Sport Psychology, 10, 281-296. doi:10.1080/10413209808406394

Masters, K., S., Ogles, B. M., \& Jolton, J. A. (1993). The development of an instrument to measure motivation for marathon running: The Motivations of Marathoners Scales (MOMS). Research Quarterly for Exercise and Sport, 64, 134-143.

Maxwell, J. A. (2005). Validity: How might you be wrong? In J. A. Maxwell, Designing Qualitative Research: An Interactive Approach (2nd Ed.) (pp. 105-116). Thousand Oaks: Sage Publications, Inc.

McAuley, E., \& Blissmer, B. (2000). Self-efficacy determinants and consequences of physical activity. Exercise and Sport Sciences Reviews, 28, 85-88. 
Morgan, W. P., \& Pollock, M. L. (1977). Psychological characterization of the elite distance runner. Annals of New York Academy of Sciences, 301, 382-404.

Nettleton, S., \& Hardey, M. (2006). Running away with health: The urban marathon and the construction of "charitable bodies." health [sic]: An Interdisciplinary Journal for the Social Study of Health, Illness and Medicine, 10, 441-460.

Nicholls, J. (1984). Conceptions of ability and achievement motivation. In R. Ames \& C. Ames (Eds.), Research on motivation in education: Student motivation Vol. 1 (pp. 3973). Cambridge, MA: Harvard University Press.

Ogles, B., \& Masters, K. (2000). Older vs. younger adult male marathon runners: Participative motives and training habits. Journal of Sport Behavior, 23, 130-143. Retrieved from PsycINFO database.

Ogles, B. M., \& Masters, K. S. (2003). A typology of marathon runners based on cluster analysis of motivations. Journal of Sport Behavior, 26, 170-180.

Ogles, B. M., Masters, K. S., \& Richardson, S. A. (1995). Obligatory running and gender: An analysis of participative motives and training habits. International Journal of Sport Psychology, 26, 233-248.

Olsen, G. D., Pracejus, J. W., \& Brown, N. R. (2003). When profit equals price: Consumer confusion about donation amounts in cause-related marketing. Journal of Public Policy and Marketing, 22, 170-180.

Raglin, J. S. (2001). Factors in exercise adherence: Influence of spouse participation. Quest, 53, 356-361.

Roberts, G. (1993). Motivation in sport: Understanding and enhancing the motivation and achievement of children. In R. N. Singer, M. Murphey, \&. L. K. Tennant (Eds.), Handbook of sport psychology (pp. 405-420). New York: Macmillan.

Ryan, R. M., \& Deci, E. L. (2000). Self-determination theory and the facilitation of intrinsic motivation, social development, and well-being. American Psychologist, 55, 68-78.

Schilling, T. A., \& Hayashi, C. T. (2001). Achievement motivation among high school basketball and cross-country athletes: A personal investment perspective. Journal of Applied Sport Psychology, 13, 103-128.

Scholz, U., Nagy, G., Shüz, B., \& Ziegelman, J. P. (2008). The role of motivational and volitional factors for self-regulated running training: Associations on the betweenand within-person levels. British Journal of Social Psychology, 47, 421-439. 
Schomer, H. H. (1990). A cognitive strategy training programme for marathon runners: Ten case studies. South African Journal for Research in Sport, Physical Education \& Recreation, 13, 47-78.

Schomer, H., \& Connolly, M. (2002). Cognitive strategies used by marathoners in each quartile of a training run. South African Journal for Research in Sport, Physical Education \& Recreation, 24, 87-99.

Scott, L. M., Scott, D., Bedic, S. P., \& Dowd, J. (1999). The effect of associative and dissociative strategies on rowing ergometer performance. The Sport Psychologist, 13, 57-68.

Scrivener, L. (2000). Terry Fox: His Story. Toronto: McClelland \& Stewart.

Seidman, I. (1998). Interviewing as qualitative research: A guide for researchers in education and the social sciences. New York: Teachers College Press.

Sparkes, A. C. (1998). Validity in qualitative inquiry and the problem of criteria: Implications for sport psychology. The Sport Psychologist, 12, 363-386.

Sparkes, A. C. (2002). Telling tales in sport and physical activity: A qualitative journey. Champaign, IL: Human Kinetics.

Summers, J. J., Machin, V. J., \& Sargent, G. I. (1983). Psychosocial factors related to marathon running. Journal of Sport Psychology, 5, 314-331.

Summers, J. J., Sargent, G. I., Levey, A., \& Murray, K. D. (1982). Middle-aged, non-elite marathon-runners: A profile. Perceptual and Motor Skills, 4, 963-969.

Taylor, A. H., \& Fox, K. R. (2005). Effectiveness of a primary care exercise referral intervention for changing physical self-perceptions over 9 months. Health Psychology, 24, 11-21.

Team in Training (2009). Retrieved February 2, 2009, from www.teamintraining.org

Urdan, T. C., \& Maehr, M. L. (1995). Beyond a two goal theory of motivation and achievement: A case for social goals. Review of Educational Research, 65, 213-243.

U.S. Department of Health and Human Services (2009). Retrieved February 13, 2009 from http://www.hhs.gov

Vallerand, R. J. (1997). Toward a hierarchical model of intrinsic and extrinsic motivation. In M. P. Zanna (Ed.), Advances in experimental sport psychology, 29, 271-360. New York: Academic Press. 
Vallerand, R., Deci, E., \& Ryan, R. (1987). Intrinsic motivation in sport. Exercise \& Sport Sciences Reviews, 15389-425. Retrieved from SPORTDiscus with Full Text database.

Vallerand, R. J., Pelletier, L. G., \& Koestner, R. (2008). Reflections on self-determination theory. Canadian Psychology, 49, 257-262.

Vineman (2009). Training programs. Retrieved February 13, 2009 from http://www.vineman.com/vinemaninformation/training.htm

Weinberg, R. S., \& Gould, D. (2007). Foundations of sport and exercise psychology. Champaign, IL: Human Kinetics.

Weiner, B. (1986). An attributional theory of motivation and emotion. New York: SpringerVerlag.

Weiner, B. (1995). Judgments of responsibility: A foundation for a theory of social conduct. New York: Guilford Press.

Wininger, S. R. (2007). Self-determination theory and exercise behavior: An examination of the psychometric properties of the exercise motivation scale. Journal of Applied Sport Psychology, 19, 471-486. http://search.ebscohost.com.libaccess.sjlibrary.org, doi:10.1080/10413200701601466

Wright, P. M., Ding, S., \& Li, W. (2005). Relations of perceived physical self-efficacy and motivational responses toward physical activity by urban high school students. Perceptual and Motor Skills, 101, 651-656.

Youn, S., \& Kim, H. (2008). Antecedents of consumer attitudes toward cause-related marketing. Journal of Advertising Research, 48, 123-137.

Zanker, C., \& Gard, M. (2008). Fatness, fitness, and the moral universe of sport and physical activity. Sociology of Sport Journal, 25, 48-65. 


\section{Appendix A}

\section{HUMAN SUBJECTS-INSTITUTIONAL REVIEW BOARD APPROVAL}

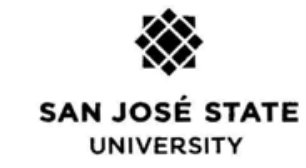

Division of Academic Affairs

Associate Vice President Graduate Studies \& Research

www.sjsu.edu/gradstudies

One Washington Square San José, California 95192-0025 Voice: $408-924-2427$ Fax 408-924-2612

www.sjsu.edu

\begin{abstract}
To: Karin A. Jeffery
From: Pamela Stacks, Ph.D. Associate Vice President Graduate Studies and Research

Date: February 17,2010

The Human Subjects-Institutional Review Board has approved your request to use human subjects in the study entitled:

"Motivations of Runners in a Cause-based Marathon Training Program"

This approval is contingent upon the subjects participating in your research project being appropriately protected from risk. This includes the protection of the confidentiality of the subjects' identity when they participate iñ your research project, and with regard to all data that may be collected from the subjects. The approval includes continued monitoring of your research by the Board to assure that the subjects are being adequately and properly protected from such risks. If at any time a subject becomes injured or complains of injury, you must notify Dr. Pamela Stacks, Ph.D. immediately. Injury includes but is not limited to bodily harm, psychological trauma, and release of potentially damaging personal information. This approval for the human subject's portion of your project is in effect for one year, and data collection beyond February 17, 2011 requires an extension request.
\end{abstract}

Please also be advised that all subjects need to be fully informed and aware that their participation in your research project is voluntary, and that he or she may withdraw from the project at any time. Further, a subject's participation, refusal to participate, or withdrawal will not affect any services that the subject is receiving or will receive at the institution in which the research is being conducted.

If you have any questions, please contact me ar (408) 924-2427.

Protocol \#S1002021

cc. Ted Butryn 0054 
Appendix B

\section{RECRUITMENT EMAIL TO CAUSE-BASED TRAINING PROGRAM STAFF}

Hi there,

Congratulations in advance on the Napa Marathon! I know how much effort goes into event weekend.

As [name of TNT Regional Director] told you, I've coached for TNT for over 10 years, and I'm now researching participant motivation in the hopes of increasing enrollment and retention.

I would like to interview up to 15 of your Napa marathon finishers. I've attached a brief description of my research, plus my contact info, so that your athletes can contact me. If you could forward this to your teams and post it on your team websites, I would truly appreciate it.

I will also drop off hard copies for you tomorrow (Thursday).

Thank you so much and have a GREAT weekend in Napa!

All the best, Karin

Karin A. Jeffery Department of Kinesiology

San José State University

karinjeffery1@gmail.com

www.sjsu.edu/people/karin.jeffery 
Appendix C

RECRUITMENT MESSAGE TO PROSPECTIVE PARTICIPANTS

Dear TNT Napa Valley Marathoner,

Congratulations on your marathon!

I’m a former TNT head coach now working at San José State University. I would like to interview 10-15 people who trained for and ran their first marathon with TNT. Interviews will take just 60-90 minutes and will be scheduled at your convenience. All personal information will be strictly confidential and you will only be identified via a code name.

Research participants will not be paid or otherwise compensated, but you might learn something interesting about your athletic self.

If you're interested in being interviewed, please contact me:

Karin Jeffery

kjeffrey@kin.sjsu.edu or karinjeffery1@gmail.com

650-799-8371 (call or text)

or via Facebook or Twitter.

Thanks! I look forward to hearing from you!

Karin A. Jeffery

Department of Kinesiology

San José State University 


\section{Appendix D}

\section{AGREEMENT TO PARTICIPATE IN RESEARCH}

\section{2 \\ SAN JOSÉ STATE UNIVERSITY}

College of Applied Sciences and Arts

Department of Kinesiology

One Washington Square

San José, California 95192-0054

Voice: 408-924-3010

Fax: 408-924-3053

www.sjsu.edu

\section{Agreement to Participate in Research}

Responsible Investigator: Karin Jeffery, M.A. Candidate, San José State University

Title of Protocol: Motivations of Runners in a Cause-based Marathon Training Program

1. You have been asked to participate in a research study investigating the perceptions and experiences of recreational runners in a cause-based marathon training program.

2. You will be asked to respond to several interview questions during one unstructured interview session. The interview will take place on a mutually convenient date between February 26 and April 30, at a mutually convenient time and location. The interview will be recorded using a digital recording device.

3. No foreseeable risks or discomforts to you, either physical or emotional, are associated with participation in this study.

4. No direct benefits to you are associated with participation in this study. However, you may indirectly benefit from a general feeling of reward from being of help to research.

5. Although the results of this study may be published, no information that could identify you will be included. You will be referred to only by a code name.

6. No compensation will be provided for participation in this study.

7. Questions about this research may be addressed to Karin Jeffery at kjbikegirl@gmail.com. Complaints about the research may be presented to Dr. Shirley Reekie, Chair, Department of Kinesiology, College of Applied Sciences and Arts, at (408) 924-3020. Questions about a research subject's rights, or research-related injury may be presented to Pamela Stacks, Ph.D., Associate Vice President, Graduate Studies and Research, at (408) 924-2427.

8. No service of any kind, to which you are otherwise entitled, will be lost or jeopardized if you choose not to participate in the study.

9. Your consent is being given voluntarily. You may refuse to participate in the entire study or in any part of the study. You have the right to not answer questions you do not wish to answer. If you decide to participate in the study, you are free to withdraw at any time without any negative effect on your relations with San José State University, with the Leukemia \& Lymphoma Society, or with Team in Training.

10. At the time that you sign this consent form, you will receive a copy of it for your records, signed and dated by the investigator.

- The signature of a subject on this document indicates agreement to participate in the study.

- The signature of an investigator on this document indicates agreement to include the above named subject in the research and attestation that the subject has been fully informed of his or her rights.

Participant's Signature

Date

Investigator's Signature

Date

\section{ate}

The Califoenia Seate University

(n)




\title{
Agreement to Participate in Research
}

\author{
Responsible Investigator: Karin Jeffery, M.A. Candidate, San José State University
}

Title of Protocol: Motivations of Runners in a Cause-based Marathon Training Program

1. You have been asked to participate in a research study investigating the perceptions and experiences of recreational runners in a cause-based marathon training program.

2. You will be asked to respond to several interview questions during one unstructured interview session. The interview will take place on a mutually convenient date between February 26 and April 30, at a mutually convenient time and location. The interview will be recorded using a digital recording device.

3. No foreseeable risks or discomforts to you, either physical or emotional, are associated with participation in this study.

4. No direct benefits to you are associated with participation in this study. However, you may indirectly benefit from a general feeling of reward from being of help to research.

5. Although the results of this study may be published, no information that could identify you will be included. You will be referred to only by a code name.

6. No compensation will be provided for participation in this study.

7. Questions about this research may be addressed to Karin Jeffery at kjbikegirl@gmail.com. Complaints about the research may be presented to Dr. Shirley Reekie, Chair, Department of Kinesiology, College of Applied Sciences and Arts, at (408) 924-3020. Questions about a research subject's rights, or research-related injury may be presented to Pamela Stacks, Ph.D., Associate Vice President, Graduate Studies and Research, at (408) 924-2427.

8. No service of any kind, to which you are otherwise entitled, will be lost or jeopardized if you choose not to participate in the study.

9. Your consent is being given voluntarily. You may refuse to participate in the entire study or in any part of the study. You have the right to not answer questions you do not wish to answer. If you decide to participate in the study, you are free to withdraw at any time without any negative effect on your relations with San José State University, with the Leukemia \& Lymphoma Society, or with Team in Training.

10. At the time that you sign this consent form, you will receive a copy of it for your records, signed and dated by the investigator.

- The signature of a subject on this document indicates agreement to participate in the study.

- The signature of an investigator on this document indicates agreement to include the above named subject in the research and attestation that the subject has been fully informed of his or her rights.

Participant's Signature

Date

Investigator's Signature

Date 
Appendix E

PARTICIPANT CONTACT INFORMATION

AND BACKGROUND QUESTIONNAIRE

Name:

Sport: Marathon run (26.2 miles)

Marathon date and location:

Charitable training organization: Team in Training (TNT)

Best way to contact you (email, telephone, other)?

Contact information:

Email address:

Phone number:

Other (please specify):

Background Questionnaire (Optional)

Previous fitness training experience:

Previous endurance event training experience:

Age:

Gender:

Race/ethnicity:

Approximate annual household income: 
Appendix F

INTERVIEW GUIDE

Responsible Investigator: Karin A. Jeffery

SJSU Protocol \#S1002021

Code Name:

Interview \#:

1. What initially attracted you to the Team in Training marathon run program?

Probes (training opportunity; connection to cause; shopping-around process;

awareness of leukemia/blood-related cancers)

2. Tell me about your entrance into the program. What were your first memories of joining TNT?

Probes (define/clarify responses; dates)

3. Tell me more about that first experience that you talked about. What was involved with that?

Probes (first informational meeting, Kickoff ceremony; specific sport)

4. So just to recap so far, [recap initial motivation for joining].

Probes (clarify language/responses; why did X affect you this way?)

5. Was there a time when your motivation started to change or evolve? What was that like?

Probes (sense of connection to cause) 
6. Tell me about what was motivating for you.

Probes (whether/how this changed)

7. Tell me about was not motivating, or amotivating, for you.

Probes (whether/how this changed)

8. Tell me about a time when you felt like not sticking with it. What was that like? Probes

9. Just to recap your motivation during the program again, [recap initial motivation when starting program, then later on].

Probes (self-efficacy; types and nature of shifts in motivation)

10. What did other people in your life think about you doing this?

Probes (family, friends, coworkers, other)

11. What specific feedback did you get about the cause itself? Were there any conversations about that?

Probes ("Why do you care about this?” "Why Team in Training?”)

12. Tell me about your relationship with the honoree(s).

Probes (how close you were; how much time you spent together)

13. Tell me about your actual marathon-training schedule.

Probes (How closely did you follow the training schedule? What were your reasons? How often did you go to team workouts versus training on your own?) 
14. Tell me about how your relationship with your honoree(s), and/or your connection with the cause, influenced your motivation to follow the marathon-training schedule.

Probes (whether/how this changed during the program; whether/how this affected your answer in question 13)

15. Tell me about running the actual marathon. What was that like?

16. Tell me about what was motivating to you during the marathon. Tell me about any experiences that stood out for you as being very positive.

17. Tell me about was not motivating for you, or amotivating, during the marathon. Tell me about any experiences that stood out for you in that way.

18. Was there a time(s) when you felt like not finishing the marathon? Tell me what that was like.

19. Is there anything else that you would like to say about your experience? 
Appendix G

REFLEXIVE JOURNAL: SAMPLE PAGES

\section{2/8/2010}

Had my bracketing interview with my adviser today. Was somewhat apprehensive going into it, because when I presented the proposal to my committee in December, they all laughed when I said “no assumptions were made for this study.” In other words, they nailed me on my obvious frustration with all the TNT cyclists I've coached over the years who didn't train (and who forced me and my staff to stay on the road with them for hours longer than should have been necessary). That's when I realized that I was going into this research with an axe to grind, to use the archaic expression.

However, the bracketing interview was a very positive experience. My interviewer encouraged me to articulate all my personal biases, expressing no judgment whatsoever. He provided a completely "safe” environment for me to answer the interview questions. Note to self: this is part of being a good qualitative researcher! Must try to do the same thing with my own interviewees.

\section{2/22/2010}

Finished transcribing the bracketing interview and emailed the transcript to my adviser. Transcription process was not as long or painful as I'd expected. I definitely see the value in transcribing one's interviews personally. 


\section{$3 / 1 / 2010$}

Emailed my former cycle team managers at LLS/TNT to ask for their help in recruiting. They immediately forwarded my message to all the run team managers. It'll be interesting to work with the runners instead of the cyclists. I wonder how much of my experience coaching TNT is sport-specific? I guess I'll find out...

\section{$3 / 2 / 2010$}

Found out by accident that the winter TNT marathon run event is THIS VERY WEEKEND. After all my procrastination on this thesis, I suddenly seem to have timed something right. Sent the LLS staff another recruitment message directed specifically at the run team managers who'll be there.

\section{$3 / 3 / 2010$}

Went through the transcript of my bracketing interview a few more times and revised my interview guide based on how my interviewer presented the questions. Think it flows better now.

\section{$3 / 9 / 2010$}

Getting responses back from TNT marathoner runners!! So fast! I can’t believe it. This is so cool. One of these marathoners, "Lisa”, asked me to call her to discuss my research, so I did. I noticed several things during the conversation:

1. I felt very awkward talking to her because I was so incredibly appreciative that she'd volunteered. I have to remember that I don't need to put myself in a onedown position just because these folks are helping me out. 
2. She works from home and she's still sore from the marathon, so for her convenience I suggested doing the interview at her house. I immediately felt weird about that; I'm a total stranger and I just invited myself into her home. She seemed okay with it, but I think going forward I need to set up interviews in more neutral places.

3. She was extremely positive about her TNT experience. She said she joined for “selfish” reasons, like I myself did, that weren’t related to the cause, but that during the program the cause became her main motivation. I'm embarrassed to admit that I didn’t want to hear this. I was expecting and hoping for someone with a negative experience, which, as we know, is what I came to expect from the cyclists I coached. This person sounds as if she’s just the opposite, that she'll validate all the assumptions in the TNT model about being inspired by the cause and the honored patients. Must remember to avoid inserting my own opinions/expectations during the interview.

\section{$3 / 15 / 2010$}

Interview 1: Lisa, in her home. As interview transcript shows, I continued feeling awkward about suggesting that we meet at her home. Lisa somewhat encouraged rather than discouraged this feeling (or perhaps it was just me responding to the sort of cues I tend to pick up on or project: I did it wrong, I'm here due to the generosity of this stranger and I've already screwed up). Lisa has two rescue pets, a dog and a cat, and I felt much better about the interview when, after about 10 minutes, the dog jumped into my lap, where he remained for the rest of the interview. As an "animal person” I felt 
validated by the fact that he approved of me, and I hoped his owner would realize that I was OK. Never quite sensed that she felt that way about me, but the dog on my lap almost made up for it - I was on his OK list even if I wasn't on hers. [And I may very well have been on her OK list too. I just assumed that I'd made an initial blunder and that nothing I did subsequently would make up for it and, as I said, she seemed to encourage this impression rather than dismiss it. It is equally likely that I misinterpreted her cues due to my own personal history.]

\section{$3 / 16 / 2010$}

Interview 2: Dave, in reserved study room in MLK. Headed into this interview determined to be professional and not repeat my mistakes with Lisa. I think it backfired because Dave is pretty much the opposite of Lisa. He is a very sweet, caring man who also seems quite shy, particularly under the fluorescent lights of the study room. I'm thinking, damn it, am I ever going to get this right? Lisa's interview was too intimate because I set it up at her house; Dave's interview was equally awkward because I set it up

in this completely sterile room. He seemed very eager to help with my research, but also very self-conscious as to whether he was "doing it right." I need to learn more about putting participants at their ease.

\section{$3 / 21 / 2010$}

Interview 3: Definitely off my game today. Didn’t want to do an interview on the weekend. Felt very out of place in affluent Los Gatos, where it seemed as if everyone else was doing recreational shopping. The interviewee, Andrea, was quite vivacious and down-to-earth. She was in her 20s (i.e. about half my age, not normally an issue for me) 
and although I enjoyed talking with her, I felt very self-conscious throughout. Also, she offered to send me four more interviewees, but nothing has come of that, so I'm wondering what I did “wrong.” Did I look (or smell) like a troll, act like a psychopath, have a wart on my nose like the Wicked Witch of the West, or something worse? I will never know.

\section{$3 / 22 / 2010$}

Interview 4: Michelle is a lymphoma survivor and an honored patient in the TNT program. She’s a very calm person and I felt much more relaxed with her than during the previous interviews. I liked her because she seemed insightful and self-aware. And she was in no way a martyr to her experience with cancer, unlike some of the people I've coached before (and would never want to coach again). I also really admired her joyous, playful attitude toward running. I wish I could cultivate that myself. She said that fundraising intimidates her but “running's the fun part.” For me, running's a source of pride and accomplishment, but it's almost never fun; it's just another thing I have to be good at. 


\section{Appendix $\mathrm{H}$}

\section{MANUSCRIPT GUIDELINES FOR JOURNAL OF SPORT BEHAVIOR}

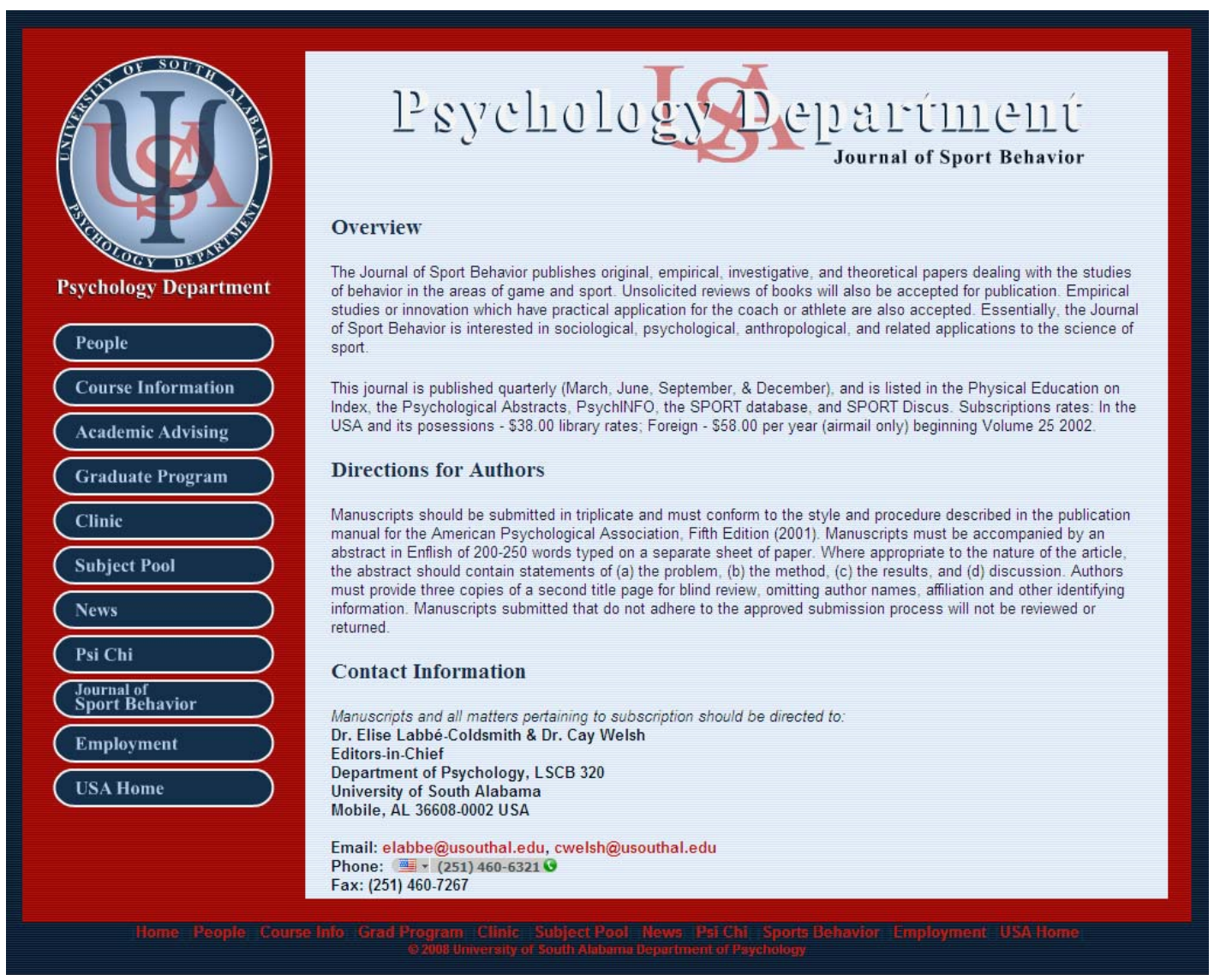

